




\section{المتطلبات التربوية لتدقيق بيئة مدرسية جاذبة بمدارس الحلقة الثانية من التعليم الأساسي في ضوء متطلبات المدرسة الباذبة}



د/ صفاء هدي اللين بهدبت



جامعـة مدينـة السـادات

استهدفت الدراسـة الحاليـة التعرف على المتطلبـات التربويـة لتحقيق بيئـة مدرسية


المدرسة الجاذبة فيما يخص ثمانية أبعاد هي: الطالب والمعلم والمنـاهج وطرق التدريس


بعض التساؤلات منها درجة توافر المنطلبات التربوية لتحقيق بيئة مدرسية جاذبة بمدارس الحلقة الثانية من التعليم الأساسي بمحافظة المنوفية، وأثر متغيرات (التخصص - مكان


وأسفرت النتائج عن أن توافر المتطلبات التربوية لتحقيق بيئة مدرسية جاذبة بمدارس الحلقة الثانية من التعليم الأساسي بالمحافظة كان بدرجة ضعيفة، وأنه توجد فروق ذات إحصائية بين مدى توفر تلك المتطلبات من وجهة نظر معلمي المواد العلمية ونظرائهم من معلمي المواد الأدبية لصالح معلمي المواد العلمية، بينما لاتو جد فروق ذات دلالة إحصائية بين مدى توافر تلك المتطلبات من وجهة نظر المعلمين في مدارس الحلقة الثانية من التعليم الأساسي بالريف ونظرائهم في الحضر . هذا وفي ضوء نتائج الدراسة وفي ضوء منطلبات


الثانية من التعليم الأساسي بمحافظة المنوفية مستقبلاً. 




التعليم حق أساسي مـن حقوق الإنسـان، وهو العمليـة الأكثر أهميـة لتميتــا كأفراد

ومجتمعات حيث يمثل حجر الزاوية لبناء حاضر مشرّف ومستقبل مثمر لأجيال قادمة.

ويواجـه التعليم في مصـر العديد مـن التحديات المحليـة والعالميـة والتـي لها انعكاسـاتها

الواضحة عليه فهنالك مجموعة من المشكلات التي تحتاج إلى حلول منها مشكلات خاصـة بالتطوير نفسـه ومشكلات خاصـة بالمنـاهج ومشكلات خاصـة بـدور العلم ومشكلات خاصــة بالأنشطة التربويـة وغياب المشاركة المجتمعية مها جعل البيئة المدرسية بيئة طاردة للطلاب وهذا يدفعنا للبحث عن مدرسة تتوافر فيها كل العوامل المساعدة والمتطلبات التربويـة لانتظام




مدرسة الاختيار تجربة أمريكية تحقق جذب الأطفال إلى المدرسة وقد اكتسبت المدرسة الجاذبة


والطلاب والمعلمين من خلال تحسين الآداء المدرسي وتوفير مجموعة من البرامج لتتمية الموارد الفردية. (Blank et al., 1996, 72) وقد أشارت العديد من الدراسات الأمريكية أن المدارس الجاذبة تزيد من فرص المشاركة للآباء كما تتضمن الاتصال الفعال للبيت والمدرسة وقد سجلت دراسة دريزكول بو9 99 ام ودراسة


الددارس مقارنة بالمدارس العادية (غير الجاذبة ). (U.S.D.E.,2004, 72 ). وتقدم المدرسة الجاذبة مناهج خاصة وتتميز بمجموعة من المميزات من حيث المناهج التعليمية المتكاملة والمميزة، وجذبها الطلاب من خارج المنطقة، والتتوع في المناخ الددرسي.




المناطق التعليمية وتقديم برامج متخصصـة وفرق تدريس متقنتة. أما المنتقدين للمدارس فإنهانهم ينزعجون من التمويل العالي واستحواذ هذه المدارس على أفضل الطلاب وعدم قدرتها على قبول


الطلاب. (Public School review,2017) 
وحيث أنـه توجد العديـد مـن المشكلات التـي تحسل دون مواءمـة التعليم المصـري

$$
\begin{aligned}
& \text { لمتطلبات العصر والتي تكمن في (حكيم، (1) • ب، 40): } \\
& \text { 1- عدم كفاية المباني المدرسية لأعداد الطلاب. } \\
& \text { r- تدني مستوى العلاقة بين المدرسة والأسرة. } \\
& \text { r- انخفاض مستوى القائمين بالتدريس وخاصة في التعليم الأساسي. }
\end{aligned}
$$$$
\text { ع - عدم إلمام معظم أولياء الأمور بكيفية رعاية أبنائهم من الناحية التعليمية. }
$$

0- عدم وجود سياسة تعليمية ثابتة وواضحة.

T- تدني العائد المادي للقائمين بالتدريس.





وحيث إن مرحلة الحلقة الثانية من التعليم الأساسي تقابل مرحلة المراهقة المبكرة وهي


وطالب هذه المرحلة يميل إلى أن يعامل معاملة الكبار وينتظر من المحيطين بـه الاعتراف






والمؤسسات الاجتماعية التي يعيش فيها وأهمها المدرسة. (خصائص ومتطلبات وسمات طالب



لذا برزت الحاجـة إلى التعرف على المتطلبـات التربويـة لتحقيق بيئة مدرسية جاذبـة




والمباني والإدارة المدرسية والمشاركة المجتمعية.

\section{مشكاسلة الدراسبـة}

تبرز قضية قصور مدار التعليم الأساسي كأحد أهم قضايا التعليم في مصر حيث


للمجتمع المصري وتزويد أبنائها - خاصة طلاب الحلقة الثانية من التعليم الأساسي - بمهارات 
الحياة وفي مقدمتها مهارات التفكير الإبداعي، ومهارات وكفاءات عصر المعرفة والتكنولوجيا المتطورة مما جعلها بيئة طاردة للطلاب.


سبيل المثال ظاهرة الدروس الخصوصية التي تربي قيمة الاتكالية في الطالب في الوقت الذي


به المطاف إلى الاستسلام لشعور مفاده أن الدراسة عبء ولا بد أن يلقيه على غيره.






مستوى المدرسة وإهدار الموارد التعليمية. هذا كما يعتبر تكس الطلاب من أهم مشكلات التعليم التي تجعل المدارس بيئة طاردة التهائه










ضعف كفاءة النظام التعليمي وعزوف الطلاب عن المدرسة. ونظراً لأهية البيئة المدرسية ومايجب أن توفره من عوامل تساعد على انتظام العملية التعليمية بدافعية جديدة نحو التعلم والإبداع بعيداً عن القوالب الصماء التي أبعدتها عن المسار




نستفيد من التطور والتقدم العلمي والتربوي الذي يوفر المتطلبات التربوية لتحقيق بيئة مدرسية


الجاذبة التي تحول المدارس من بيئة طاردة للطلاب إلى بيئة جاذبة تتميز بالخصائص التالية:


(بيئة مدرسية آمنة يكون الطالب فيها هو محور العملية التعليمية ومركز اهتمامها. 


$$
\begin{aligned}
& \text { ( ) معلم ذو قدرات ومهارات عالية يتم تتميته مهنياً بشكل مستمر . } \\
& \text { x) مناهج متطورة تواكب احتياجات الطالب ومتطلبات المجتمع. }
\end{aligned}
$$

( أسـاليب وطرائق تدريس متتوعة تتناسب مـع النظام التمثيلي للطالب ونوع ذكاؤه وتراعي

$$
\text { الفروق الفردية بين الطلاب. }
$$



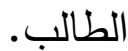

(1) قيادة مدرسية فعالة لتوطيد العلاقة بين المدرسة والطالب وبينها وبين أسرة الطالب. (ج مشاركة مجتمعية فعالة من خلال إتاحة المشاركة والانفتاح على المجتمع بكل قطاعاته. ومن ثم تسعى الاراسة الحالية للإجابة على السؤال الرئيسي التالي: × ما درجة توافر المتطلبات التربوية لتحقيق بيئة مدرسية جاذبة بمدارس الحلقة الثانية من لن


وبيفرع من هذا السؤال الرئيسي التساؤلان الفرعيان التاليان: ا - مـا أثر متغيرات (التخصص - مكان المدرسـة) على مستوى توافر المتطلبات التربويـة لتحقيق بيئة مدرسية جاذبة بمدارس الحلقة الثانية من التعليم الأساسي بمحافظة المنوفية؟


بمحافظة المنوفية في ضوء متطلبات المدرسة الجاذبة؟

\section{أهـــــاف الدراســـة:}



1- التعرف على درجة توافر المتطلبات التربوية لتحقيق بيئة مدرسية جاذبة بددارس الحلقة الثانية من التعليم الأساسي بمحافظة المنوفية. r- التعرف على أثر متغيرات (التخصص - مكان المدرسة) على مستوى توافر المتطلبات التربوية لتحقيق بيئة مدرسية جاذبة بمدارس الحلقة الثانية من التعليم الأساسي بمحافظة


r- التعرف على التصور المقترح لتحقيق بيئة مدرسية جاذبة بمدارس الحلقة الثانية من التعليم الأساسي بمحافظة المنوفية في ضوه متطلبات المدرسة الجاذبة. 


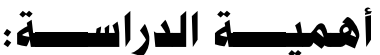

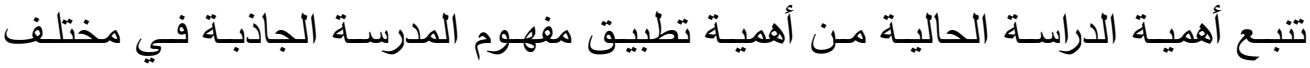

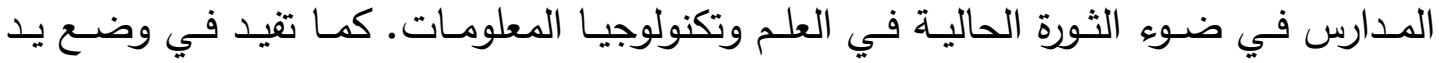

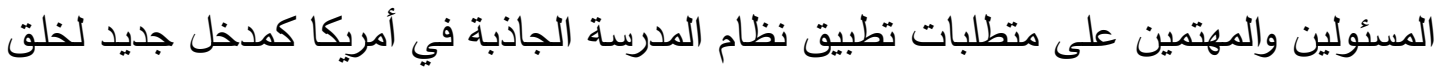

$$
\text { بيئة مدرسية جاذبة في المدارس المصرية. }
$$

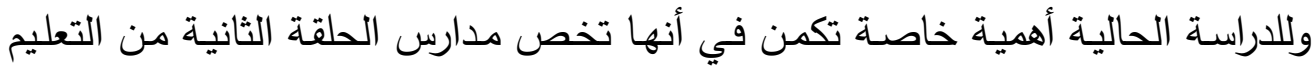

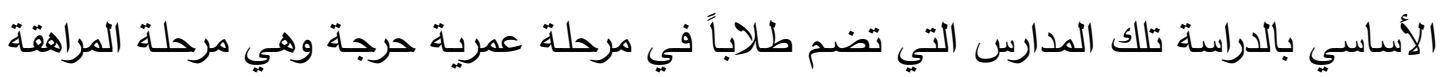

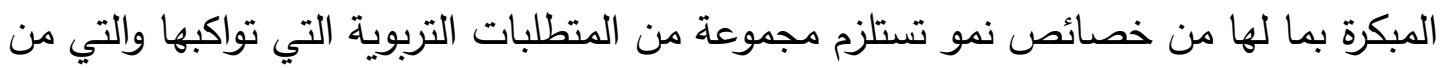
المفترض أن تتوفر في هذه المدارس لتصبح جاذبة للطلاب.








الاتصال من أجل توثيق العلاقة لتحقيق الأهداف التربوية المنشودة.







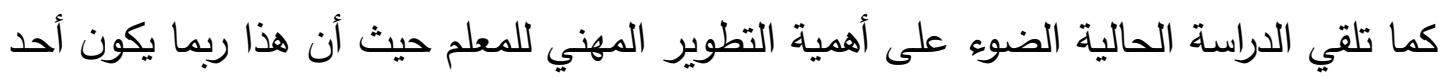
أهم عوامل جذب الطلاب للمدرسة.

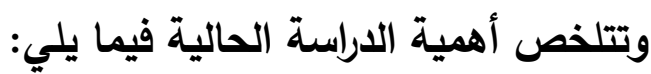

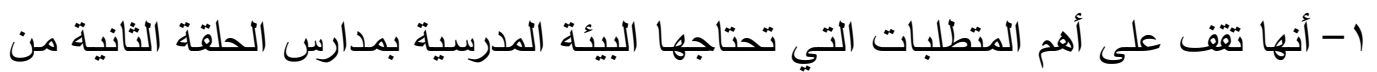

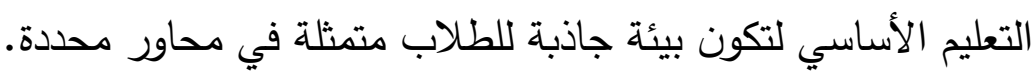

r- أنها تعنى برأي المعلم العنصر الأهم في العملية التعليمية.

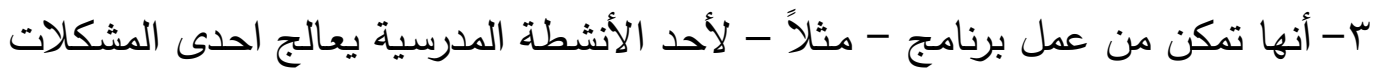

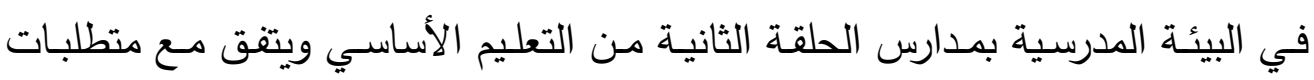
المدرسة الجاذبة بناءً على نتائج الدراسة. ع - أنها تعلي من قيمة تطبيق العلم وليس مجرد الإيمان به فالإيمان ما وقر في القلب لبـانب وصدقه العمل. 


\section{حسدود الدراســـة}

أ) الحدود الموضوعية: اقتصرت الدراسة الحالية على معلمي الحلقة الثانية للتعليم الأساسي،




طرق التدريس، الأنثطة، المباني، الإدارة الددرسية، المشاركة المجتمعية.



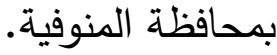
ج) الحدود الزمانية: تمت إجراءات الدراسة في العام الدراسي 2015 /2016.

\section{مصطاد}

المتطلّبات: جمع متطلّب وهو اسم مفعول من تطلّب ويعني أمر أو عمل يطلب تحقيقه، وهو

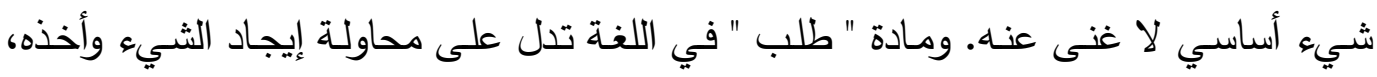

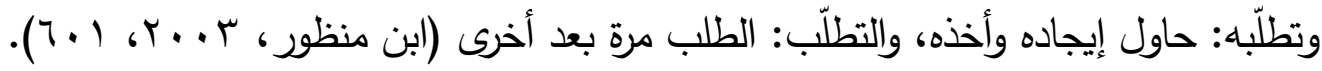

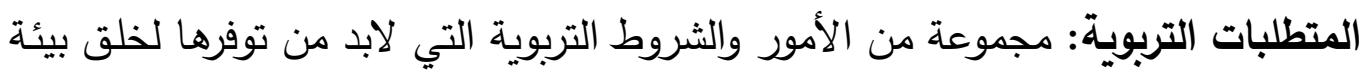

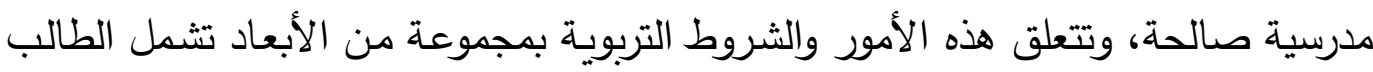
والمعلم والمناهج وطرق التدريس والأنشطة والمباني والإدارة الددرسية والمشاركة المجتمعية.

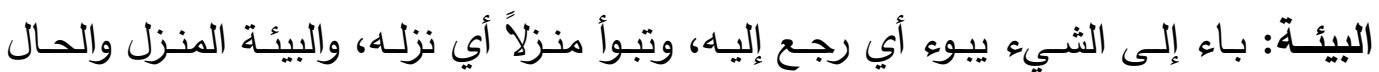

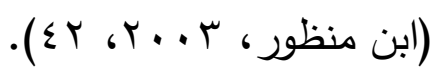

البئة المدرسية: الإطار البيئي المحيط بالطالب داخل المدرسة والذي تعمل فيه الددرسة

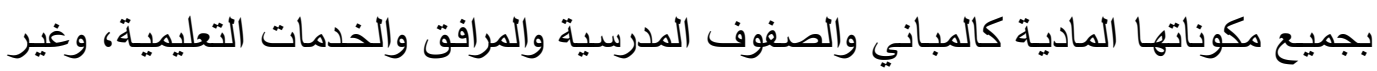

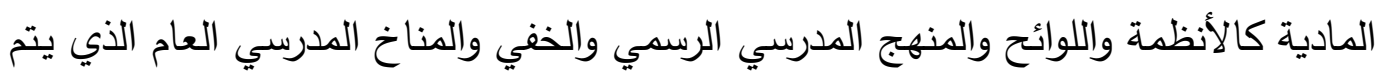

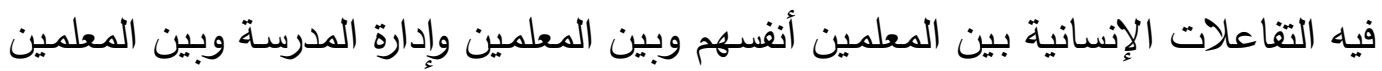



كما عرفها (Hoy \& Miskel,2005,185) بأنها مجموعة الخصائص الداخلية التي كائي

$$
\text { تميز مؤسسة تعليمية عن غيرها والتي تئثر على سلوك كل عضو فيها. }
$$


تتضمن العلاقات بين الطلبة من جهة والمعلمين من جهة أخرى وبين الطلبة والمعلمين أنفسهح 
والإدارة المدرسية والموارد والأبنية والمرافق المدرسية إذ تؤثر جميعاً في مخرجـات المنظومـة المدرسية كماً ونوعاً.

وتـرى الباحثـة أن البيئسة المدرسـية هـي مجموعـة الخصـائص التي يدركها الطـلاب

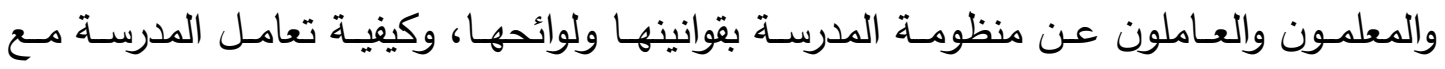
المعلمين والطلبة والبيئة المحيطة مما يؤثر بشكل مباشر على مخرجات العملية التربوية. وقد تكون البئية الددرسية إيجابية مشجعة على التعلم وقد تكون سلبية منفرة للطلبة.



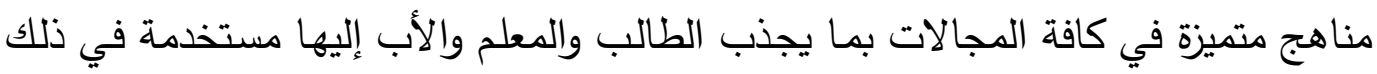

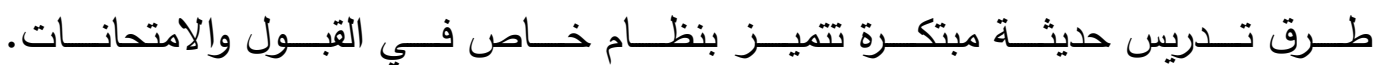
(Guthrie, James, 2003, 152-153).

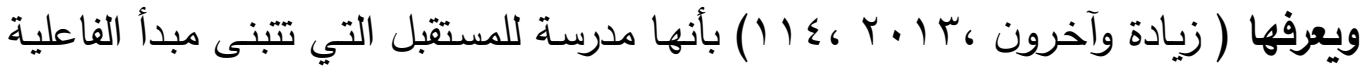

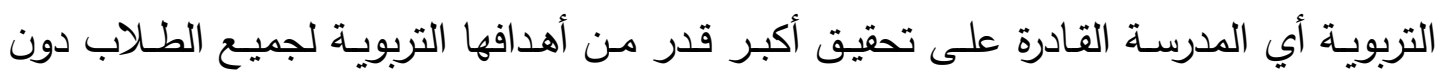

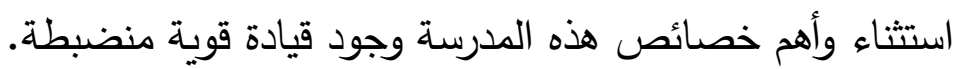

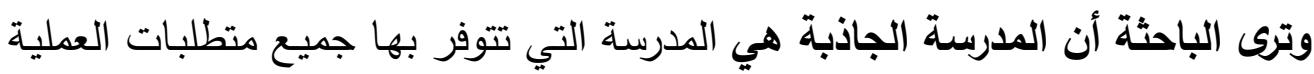

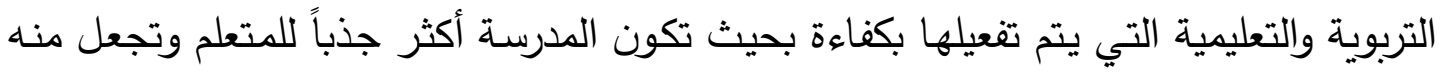
متعلماً متميزاً على كل المستويات المعرفية والمهارية والوجدانية.

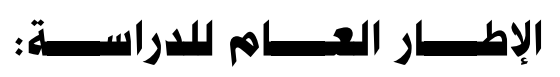

تتضمن الدراسة إطارين أساسيين هما:

$$
\text { أولاً: الإطــــار النظـــــري: }
$$

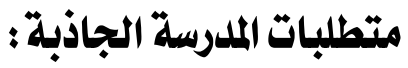

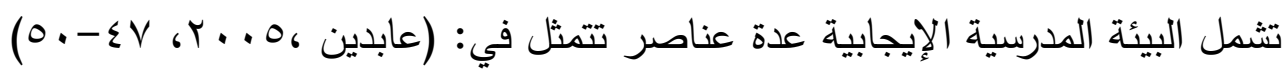

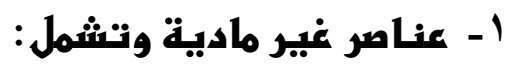

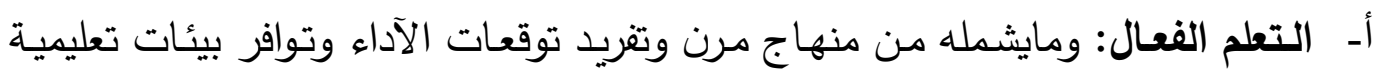
مختلفة ونشاطات غير منهجية متعددة ونظام مكافأة متنوع. 
ب- عناصر غير مباشرة تشمل الثقة بالنفس والاحترام والروح المعنويـة المرتفعة والتماسك واستمرار النمو الدراسي والاجتماعي.

r - عناصـر تتعلق بالعمليـة التربويـة وتشمل أسلوب حل المشكلات وتحديث أهداف المدرسـة ومراجعتها بشكل مستمر وحلاً إيجابياً للصراعات ونظام وتواصل فعال وإدارة تشاركية في صنع القرار وشفافية في العمل واستعداداً للمساءلة والتقويم الخارجي لما يجري في المدرسة. ץ- عناصـر ماديـة وتضــ كل مـايتعلق بينـاء المدرسـة مـن موقـع وترتيـات وأثاث ومختبرات

$$
\text { وحدائق وملاعب وغيرها. }
$$

ولا شك أن البيئة المدرسية الجاذبة تميز مدرسة ما عن غيرها من المدارس لما يتضح فيها من نواحي فنية وإجرائية مميزة في تنفيذ عمليات التعلم وممارسة الأنشطة والإرشاد والإدارة وتوافر الإمكانيات المادية بمختلف أنواعها.

ويمكن إيجاز مزايا المدارس الجاذبة فيما يلي: ( Harris,R.M.,1993,90) ا - ارتفاع التحصيل الأكاديمي للطلاب وإعداد متعلم دائم التعلم. r- ارتفاع معدل الالتحاق بها وزيادة الطلب عليها وانخفاض معدل التسرب والرسوب. ب-زيادة مشاركة أولياء الأمور والانفتاح على المجتمع بكل قطاعاته. ع - تطبيق المناهج الدراسية الواسعة والبرامج التعليمية التي تراعي الطابع الشخصي. 0- إيجاد بيئة تعليمية غنية بالمثيرات المفضلة لدى الطلاب. ج- تهيئة الظروف المناسبة للتطور المهني للمعلم الأكثر استعداداً للتطوير • ويذكر كلينثي(Clinchy,E.,1995,47) أن الأساس في النموذج الإداري للمدرسة الجاذبة

هو تمكين الآباء والمعلمين والطلاب وبالتالي تحسين إدارة المدرسة وزيادة العلاقات الاجتماعية. وطبقاً للموقع الرسـي للمدارس الجاذبـة فإن رسـالة المدرسـة الجاذبـة أن تقدم القيادة المبتكرة للقيادة التعليمية التي تثجع على المساواة والتفوق الأكاديمي لجميع الطلاب في جميع المدارس. هذا وينوه الموقع عن الأهداف التظيمية للمدرسة الجاذبة وهي كالتالي: Magnet) .schools of America ,2016)

$$
\text { 1- تعزيز ودعم المساواة والإنصاف والتوسع وتطوير المدارس الجاذبة. }
$$
ץ- تشجيع المؤسسات التجارية للمشاركة في الأنشطة في المدارس الجاذبة وتقديم الدعم لها من الناحيتين النظرية والمادية. 
؟ - تشجيع الحكومة لتمويل برامج المدارس الجاذبة وزيادة مقدار هذا الدعم.

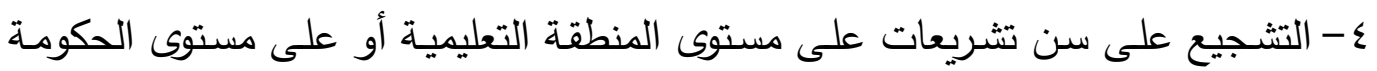

$$
\text { من شأنها أن تدعم وتطور المدارس الجاذبة. }
$$

ه- تقديم معومات عن مزايا المدارس الجاذبة وأولياء الأمور والمجتمع المحلي.

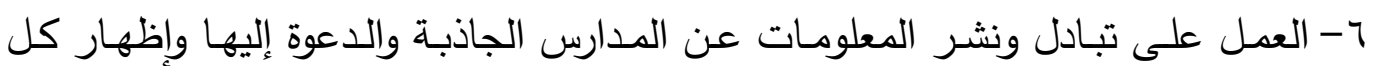
مايتعلق بها وبرامجها بشفافية. وتقوم المدارس الجاذبة على خمسة ركائز أساسية وفقاً لما ورد بموقع المدارس الجاذبة وهي كالتالي: (2016, Magnet schools of America mission \& beliefs).

$$
\text { ا - التنوع. }
$$

r- ب المناهج المبتكرة والتتمية المهنية.

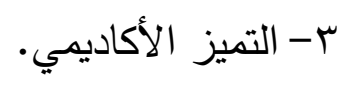

ع - الأنظمة التعليمية عالية الجودة.

$$
\text { 0- الأسرة والمشاركة المجتمعية. }
$$

ويلاحظ أن هذه الركائز الخمسة تشمل إما صراحةً أو ضمنياً مدخلات النظام التعليمي

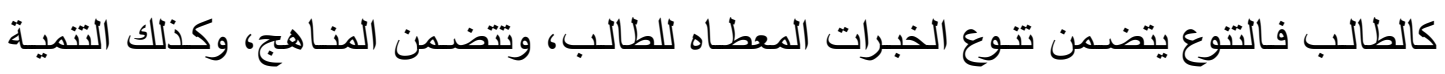

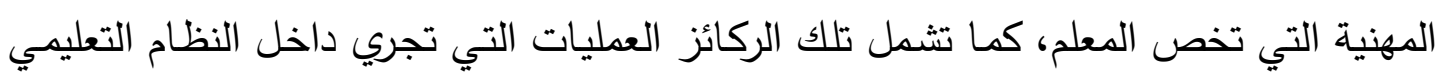

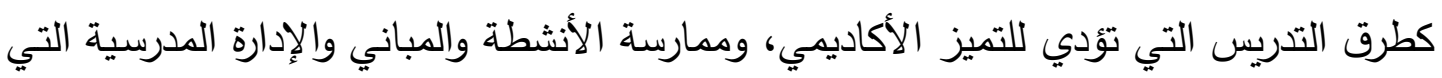
هي جزء من أي نظام تعليمي عالي الجودة، وكذلك المشاركة المجتمعية. ويمكن توضيح هذه المدخلات وتلك العمليات فيما يلي:

$$
\text { ا } 1 \text { - الطالـــبـ }
$$

تستقطب المدرسة الجاذبة طالباً ذا مواصفات خاصة ومختلفة من مدرسة لأخرى، وعليه

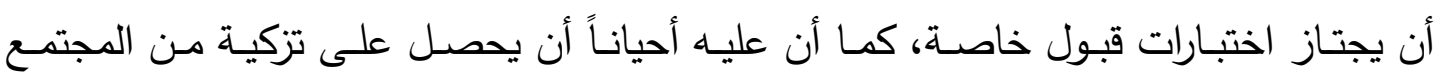

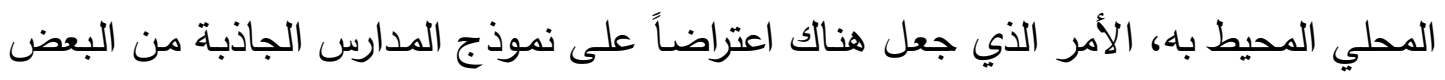

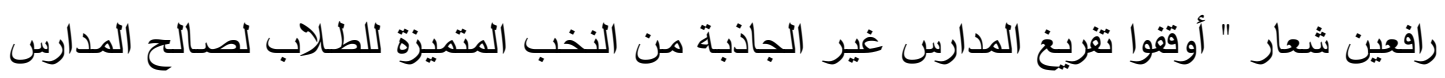

الجاذبة ". (Goldring etal. , 2002, 13)



إن للمعلم أهمية كبيرة في العملية التربوية بشكل عام والعملية التعليمية الإبداعية بشكل

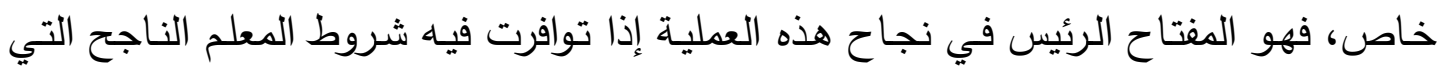


تتضمن اضطلاعه بمسئولياته من تهيئة المناخ الذي يقوي ثقـة المتعلم بنفسه، وينهي روح الابتكار والإبداع لايه، ويهذب سلوكه، وينشط تفكيره، ويفتح آفاق التحصيل والإنجاز لديه. ومن ضمن أهم المواصفات بالنسبة للمعلمين في المدارس الجاذبة: United States

Department of Education, 2004, 14-15)

أن يحمل المعلمون درجة البكالوريوس في مجال التخصص الذي يدرسونه. أن يحصل المعلمون على الترخيص لمزاولة المهنة في ذات العام.

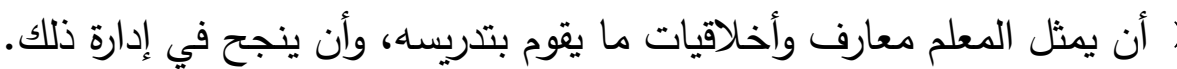
التأهيل والتدريب والإبداع تعتبر أهم ملامح وصفات المعلم للعمل في المدارس الجاذبة.

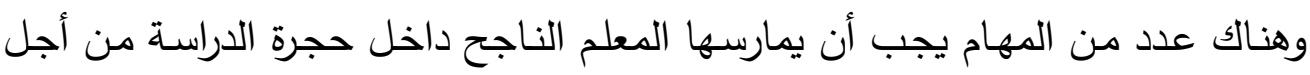

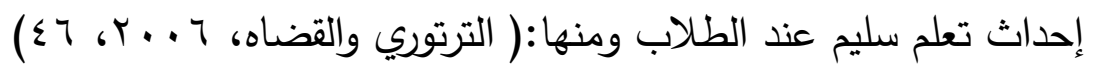
الإبداع في تتظيم حجرة الدراسـة بشكل يوفر بيئة تعليمية يجد فيها المتعلمون القبول

$$
\text { والتشجيع والاحترام. }
$$

ملاحظة المتعلمين والتعرف على سلوكهم يتيح له فرصة الاكتشاف والتجريب.

مواجهة المشكلات السلوكية والعمل على حلها بالتعاون مع المرشد الطلابي.

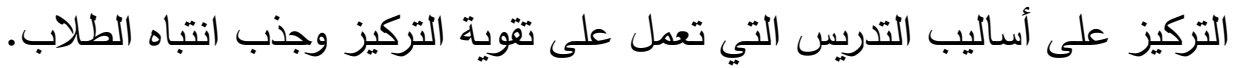

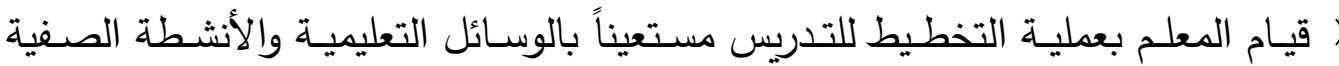
الإثرائية لتحقيق هدفه من العملية التعليمية. إثارة اهتمام وميول الطلاب بمحتوى المـادة التعليميـة من خـلال الإيمـاءات والحركات فلات والتتويع في استخدام التتنيات والوسائل التعليمية الحديثة.

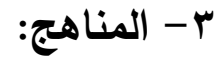

تقدم المدارس الجاذبة مناهج وموضوعات في الرياضيات والعلوم والتكنولوجيا واللغات

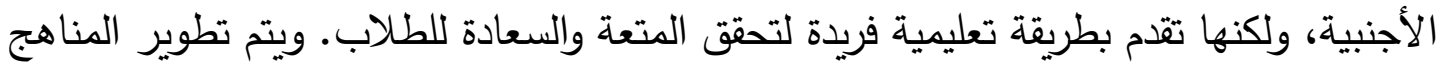
من خـلال زيـادة التمويل حيث تمول المدارس الجاذبة بأكثر من قنـاة من التمويل الحكومي

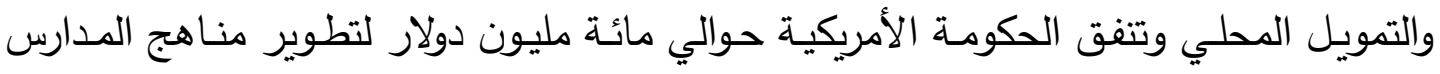

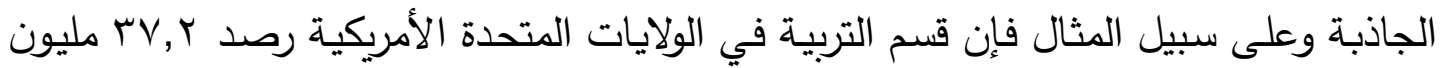

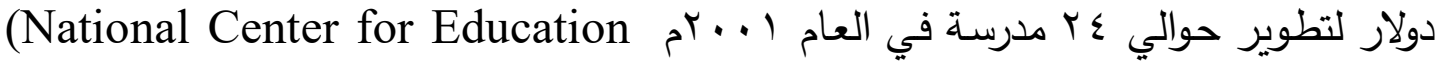


ويشير البعض أن المدرسة الجاذبة قد أنثئت في بدايتها كأحد آليات القضـاء على لـى

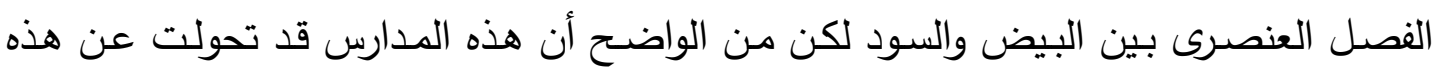
النقطة واتجهت بكل قوتها إلى تتويع البيئة المدرسية وتجديدها مما يضمن جذب الآباء والطلاب الناب

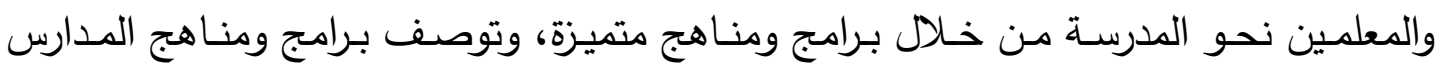
الجاذبة بخمس صفات أساسية هي: (Public School Review, 2016)

$$
\text { (الكفاءة }
$$

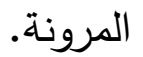

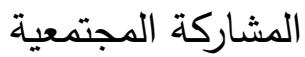
زيادة المواطنة.

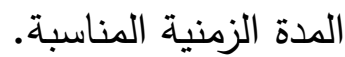

ويذكر كل من يونج وكلينشى بو99 ام أن الجذور التاريخية لمناهج المدارس الجاذبة

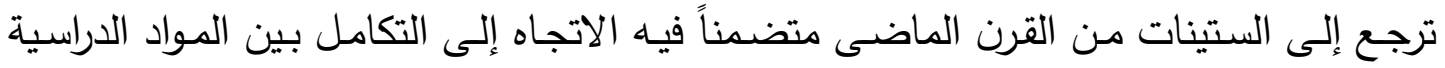

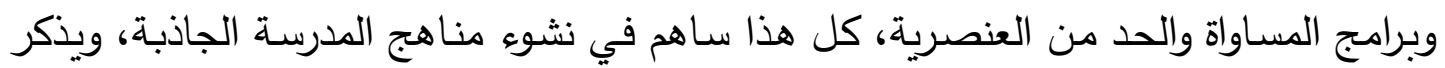

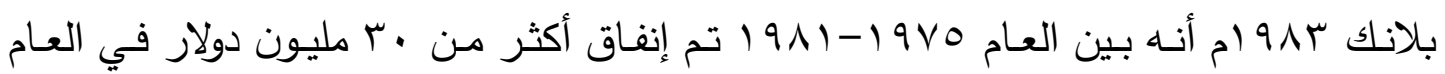

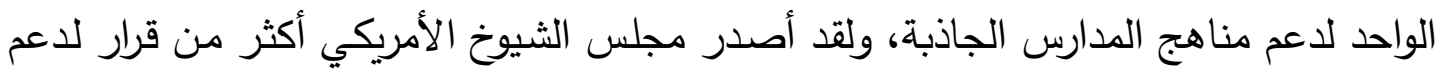
مناهج المدارس الجاذبة تركزت في أربع نقاط: (National Education Association, 2007, 66).

أ) أن تسهم منـاهج المدرسـة الجاذبة في القضـاء على الانعزالية بين الطلاب داخل

$$
\text { المدرسة الجاذبة وخارج المدرسة في أحيائهم. }
$$

ب) تشـارك المؤسسـات التربويـة في تصميم وإنتـاج منـاهج المدارس الجاذبـة للوصـول بالطلاب إلى أقصى تحصيل دراسي ممكن. ج) أن تركز المناهج على زيادة المشاركة المجتمعية. د) يتحدد دعم هذه المدارس بقدرتها على تتفيذ هذه المناهج والبرامج.

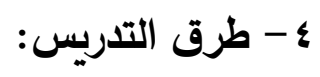

يستخدم المعلمون في المدارس الجاذبة العديد من طرق التدريس الجديدة والمتنوعة التي قد تختلف من مدرسة جاذبة إلى مدرسة أخرى لكنها تهدف إلى الإثارة والتشويق وزيادة تحصيل الطلاب. (Reed, V., 2004,95) 
وتستخدم المدارس الجاذبة طرق تدريس حديثة ومتنوعة تطبق على مدى واسع في أكثر من مدرسة جاذبة فمن خلال طرق التدريس يتم توصيل المعلومة للطلاب خاصة ونحن نعيش

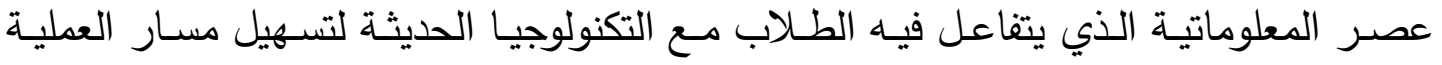

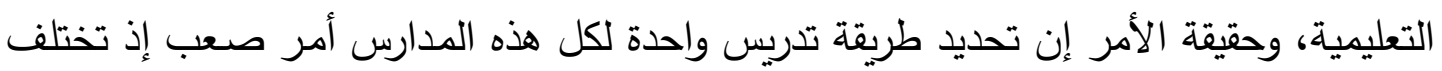

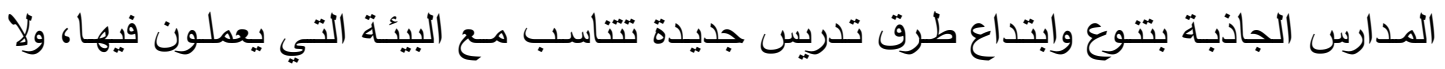

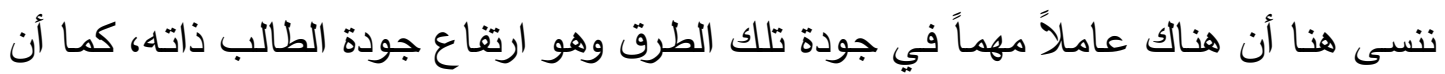

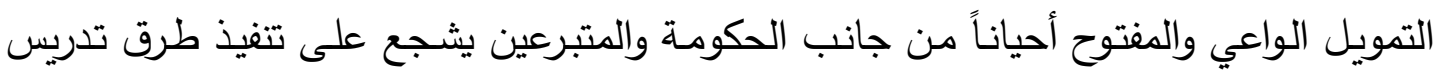

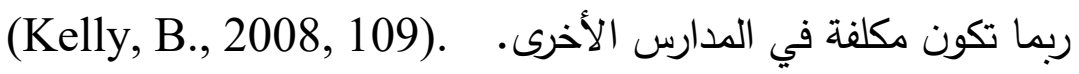

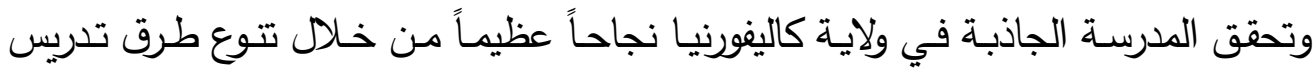

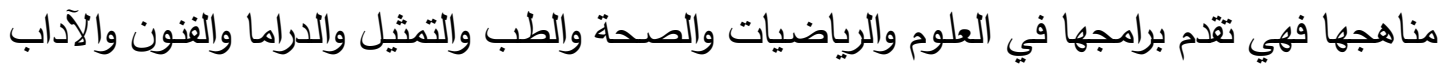

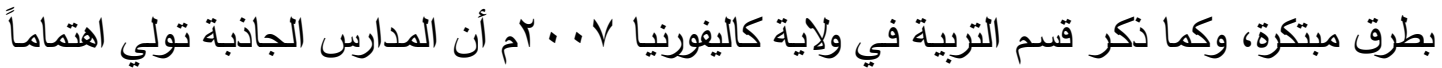

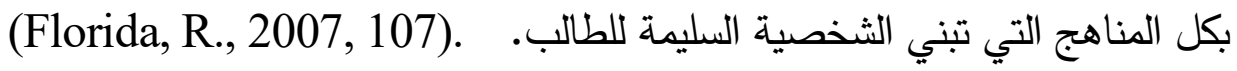
وعلى سبيل المثال فإن مدرسة زامورانو الابتدائية في سان دياجو تولي اهتمامها بالفنون

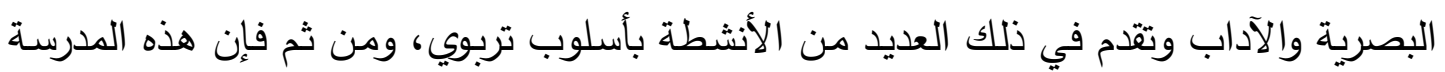

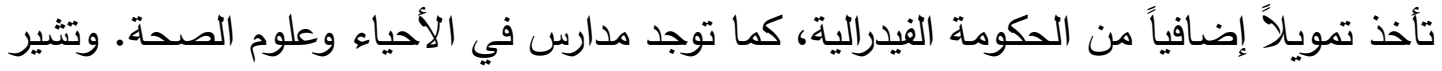

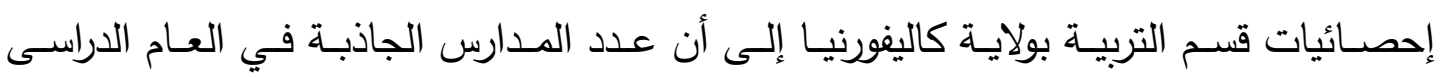

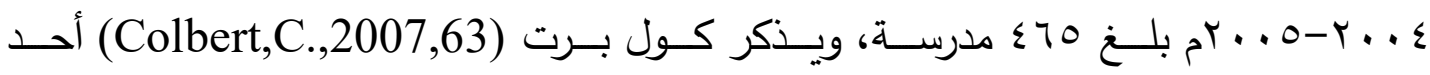

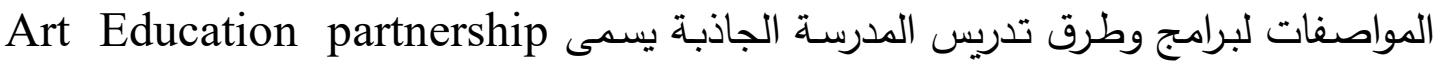
والذي يتكون من خمسة أجزاء متكاملة تتمثل في: القراءة وتتمية اللغة: ويتكون هذا ( المديول ) من أساسيات اللغة وكتابة اللغة بالحروف والكلمات والجمل والأصوات والتركيبات المختلفة بالإضافة للإنشاء والتحدث ومهارات

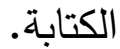
الرياضيات: ويشمل بعض المهارات الأساسية لفهم الرياضيات وبعض الأفكار والمفاهيم والتي غالباً ما تدرس مع الموسيقى.

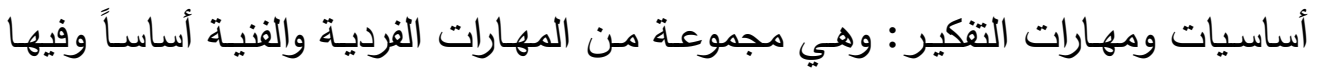
يتعلم الطالب بطريقة فردية من خلال حل المشكلات والتنكير الإبداعي. 
الدافعية للتعلم: ويتكون من مجموعة من الفنون والأفكار التي تسهم في الإقبال على

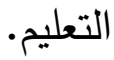
بال السلوك الاجتماعى الفعال: وفيها يتعلم الطالب مجموعة من الأنشطة التي تدعم نمو

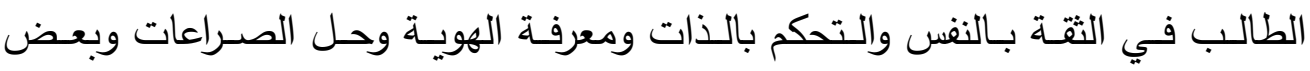

$$
\begin{aligned}
\text { ه- الأنثطـــة المهارات الاجتماعية. } &
\end{aligned}
$$

تعد الأنشطة التربوية من أهم جوانب العملية التعليمية التي تعمل على بناء الطالب، التها، باعتباره أهم عضو في المجتمع المدرسى، وقد كثرت الثكوى من فساد العملية التعليمية وقلة

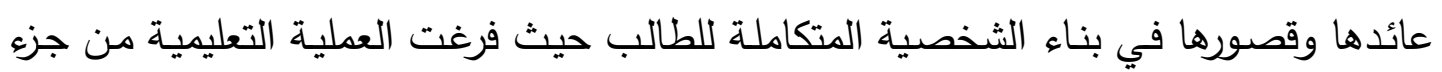

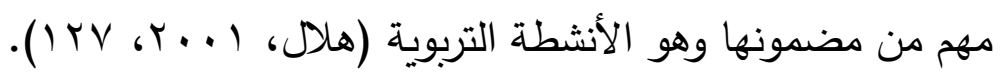
ويرى " جون ديوي " John Dewey" أن النموذج الإيجابي لما ينبغي أن يكون عليه

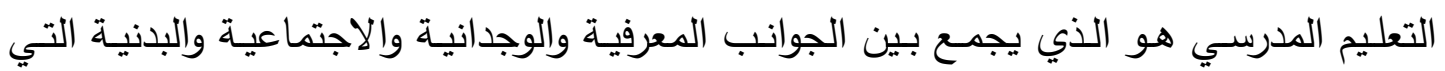

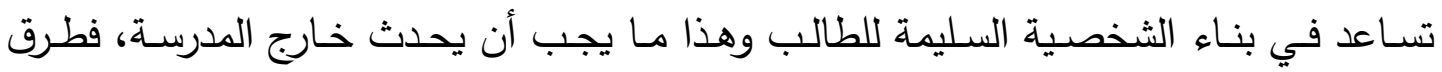
التدريس التي يثبت نجاحها في المدارس هي الطرق التي تعتمد على مواقف من النوع الذي يثير الأفراد للتفكير في حياتهم العادية. (Kelly, B., 2008, 118).

لذلك تعالت الصيحات بضرورة عودة النشاط التربوي للمدرسة، وإفساح الدجال لـه أثناء

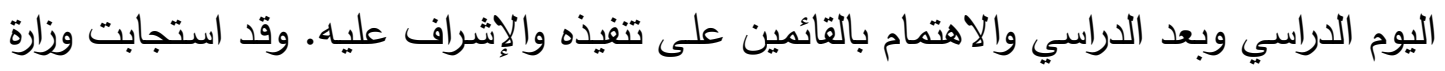

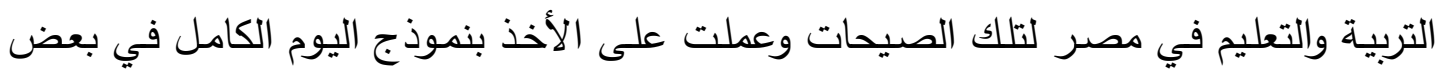
المدارس، وذلك بهدف إتاحة الفرصة لممارسة مختلف أنواع الأنشطة خلال اليوم الدراسي. وترى الدراسة أن النموذج الإيجابي لما ينبغي أن تكون عليه عملية التعليم هو الذي الذي التئه

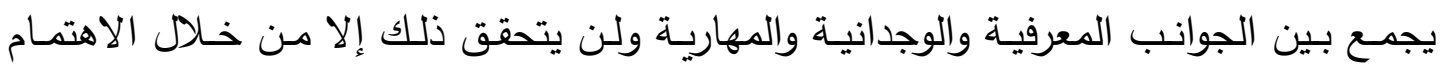

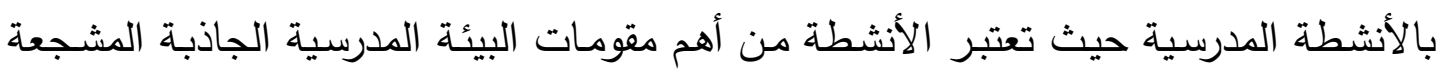

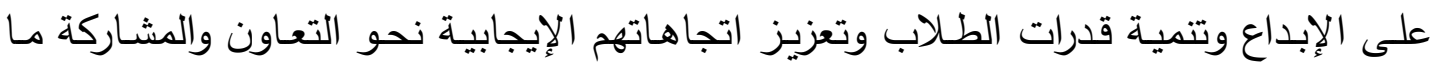
يعمل على تدعيم الارتباط بين المدرسة والبيئة المحلية التي تقع فيها ومن ثم توفير نموذج الإيجا مدرسي جاذب للطلاب. 
يعد المبنى المدرسي أحد الأركان الأساسية للمدرسة لأداء العملية التعليمية ولكي تتم

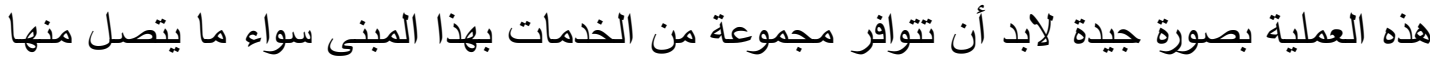
بالنشاط التعليمي أو بإداريات المدرسة أو بمرافقها الصحية. وبقدر ما يكتمل للددرسة من إمكانيات ومقومات مادية بقدر ما تتحقق الفرصة للنمو لفرافي المتكامل لطلابها، ومن المقومات المادية ما يتصل بالخدمات المدرسية ومن أهم الخدمات التي لئي

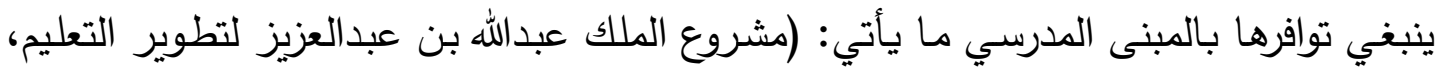

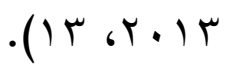

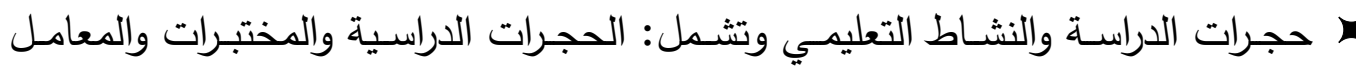
والملاعب والمكتبة وحجرة التربية الفنية وحجرة التربية الموسيقية.

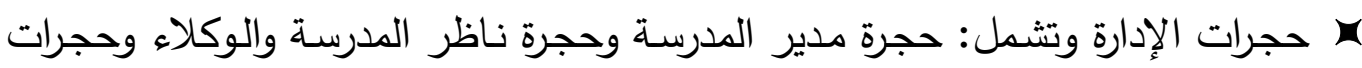
المدرسين وحجرة الإخصائي الاجتماعي والمرشد الفني وحجرة الإداريين وحجرة العمال وحجرة أمين التوريدات ومخزن الأثاث المدرسي. المرافق الصحية وتشمل: دورات المياه ومكان الوضوء ومرفق مياه الثرب.

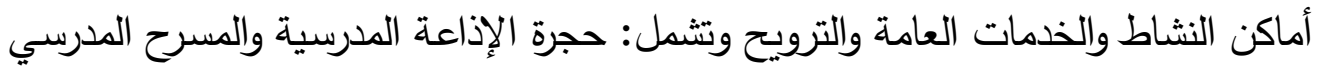
وحجرة الألعاب الرياضية والحديقة وغرف مصادر التعلم والاتصال السمعي والبصري. بالإضافة إلى ضرورة توفر شروط صحية هامة في المبنى المدرسي كالإضاءة والتهوية

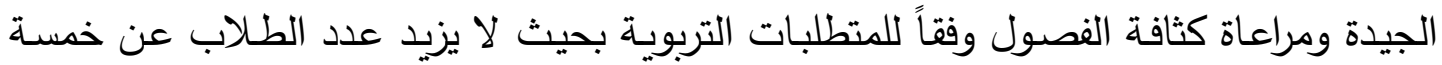
وعشرين طالباً في الفصل. وتوافر هذه الخدمات يساعد على تفاعل أطراف العملية التعليمية

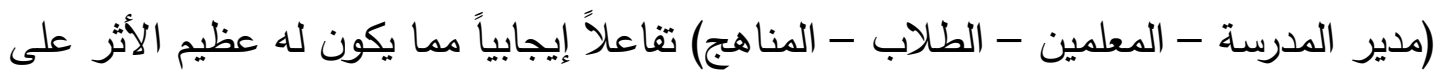

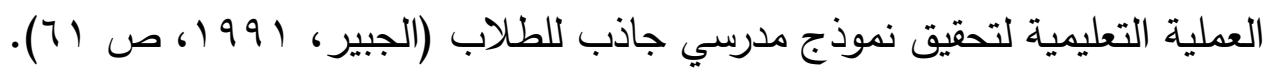

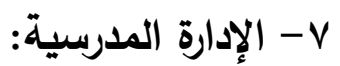

تتسم المدرسة الجاذبة بأنها تعتمد على نموذج إداري مميز لها، ويذكر كلينشي 990 ام

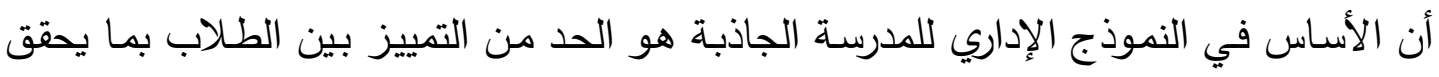

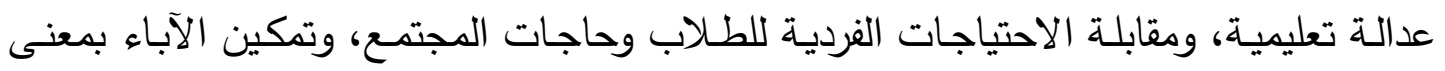


أنهم من يحددون قائمـة الخيارات التعليميـة التي ينبغي أن تقدمها المدرسـة لأبنائهم، وزيـادة التفاعل بين المعلمين والطلاب وزيادة العلاقات الاجتماعية بين إدارة الدرسة والمجتمع المحلي وبالتالي تحسين إدارة المدرسة. (Clinchy ,E.,1995, 47-50) وطبقاً لما ذكر دي بري 919 ام فإن الخطوة الأولى في بناء النموذج الإداري للددرسة

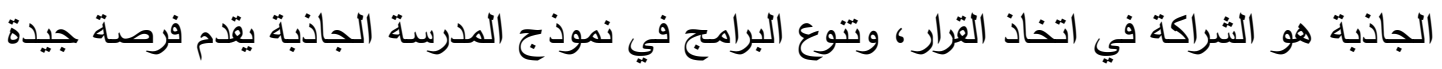

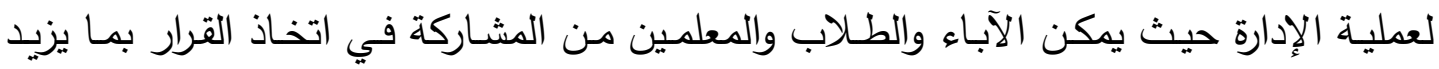
الشراكة بينهم. (DePree, M., 1989, 12)

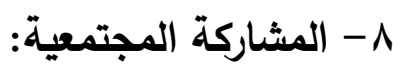

أشارت العديد من الدراسات الأمريكية إلى أن المدارس الجاذبة تزيد من فرص المشاركة

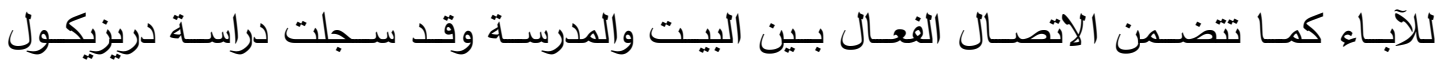

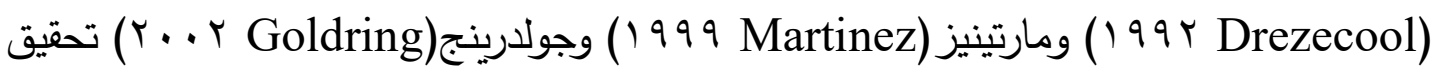

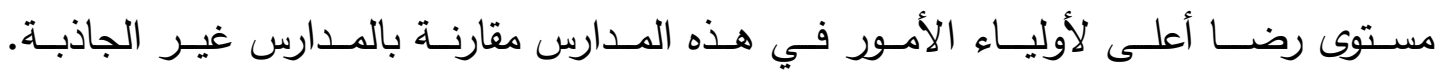
.(United States Department of Education, 2004, 104) ويتتوع تمويل برامج المدارس الجاذبة مـا بين التمويل الحكومي والتبرعات من رجال

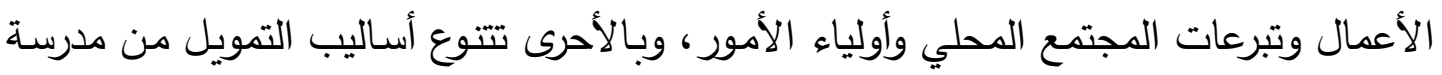
إلى أخرى ومن عام إلى آخر لكن يبقى الجزء الأكبر من التمويل من جانب الحكومة أو الولاية

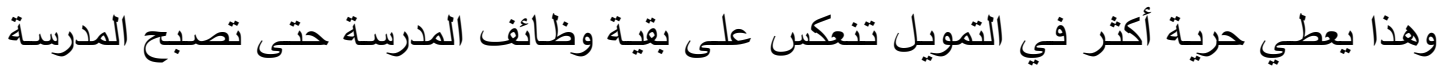
قادرة على جذب طلاب ينمون بها وتتمو بهم. (Colbert,C.,2007,18)

\section{مرحلة الحلقة الثانية من التعليم الأساسي واحتياجات الطلاب بها :}

وهذه المرحلـة هـي الوسـطى بـين ثـلاث مراحل: مرحلــة الحلقـة الأولـى مـن التعليم

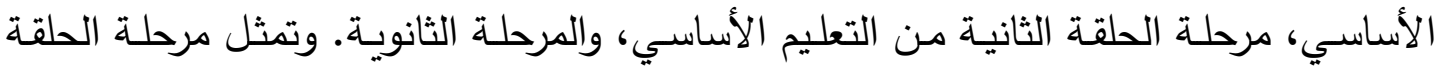

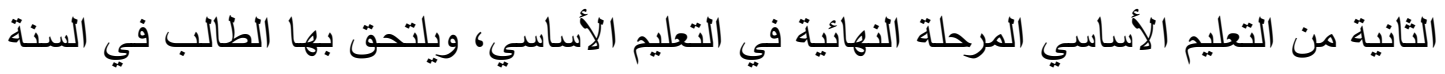

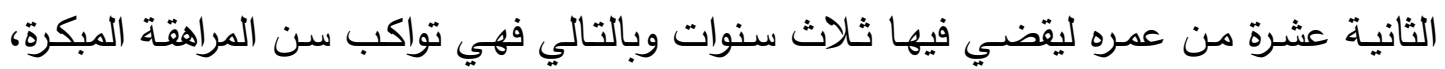
وبناء على ذلك فمن الدفترض أن تراعي البيئة المدرسية بكل مكوناتها النمو الثامل للطلاب في لهني هذه المرحلة وفقاً لخصائص النمو التي تتميز بها هذه المرحلة عن غيرها. 
هذا وتعتبر هذه المرحلة مرحلة النمو السـريع المتواصـل التي تحدث فيها تغيرات كثيرة للطلاب من النواحي الجسمية والفسيولوجية، كما تحدث أيضاً تغيرات عقلية وانفعالية بالغة العمق تؤدي إلى اختلاف التوازن الانفعالي والاجتمـاعي للطـلاب فنجدهم يلجأون إلى البعد عن الواقع والهروب إلى عالم الخيال وأحلام اليقظة. كذلك فإن من خصائص هذه المرحلة صعوبة التوافق مع عالم الكبار خصوصاً أولئك الذين يمثلون السلطة الضـابطة كالآباء والمعلمين والمديرين، ومن ثم يلجـأون إلى مجموعـة الرفـاق فيتضـح مـيلهم للجنس الآخـر، ويشـعرون بـأنهم جديرين بالحب والإعجـاب، ويلعبون أدوار القيـادة والزعامـة والبطولـة والمغـامرة مـع رفقائهم ويبحث كل منهم عن

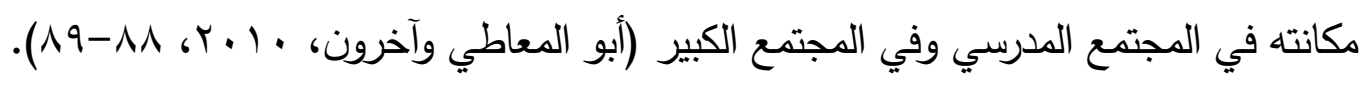
كمـا تمثل مرحلـة الحلقـة الثانيـة مـن التعليم الأساسـي مرحلـة انتقاليـة هامـة في حيـاة الطالب، فهي بالنسبة لبعض الطـلاب مرحلـة نهائيـة تعدهم للاضطلاع بأعباء الحيـاة، وهي بالنسبة لبعضهم الآخر موصلة إلى المرحلة الثانوية من التعليم.

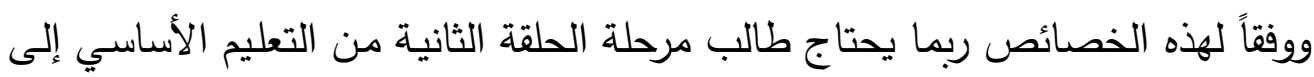

$$
\text { برامج تهتم بـ: (خصائص نمو التلاميذ في المرحلة الإعدادية ) }
$$
ا - تشـيعه على اختيـار ألـوان النشـاط الرياضـي الذي يرغب فيـه فهو يميل إلى الألعـاب الجماعية المنظمة. r- التربية الجنسية فهي ضرورية في هذه المرحلة مع معاونته على أن يعبر عنها وما يقلقه منها وتبصيره بها. ب- رغبته في المساهمة في أنواع الخدمات التي يمكن أن يؤديها كمواطن في بيئته. ع - إتاحة الفرصة له للتعبير عن ذاته بالأنشطة الثقافية والإذاعة المدرسية والحفلات وغيرها. 0- إتاحة الفرصة لله لإيجاد علاقات طيبة بينه وبين بيئة المدرسة بشكل عام.

\section{الدراســات السابة} ويتم عرض تلك الدراسات وفقا للترتيب الزمنى لها من الأقدم إلى الأحدث وتتقسم إلى دراسات عربية ودراسات أجنبية كالتالي:

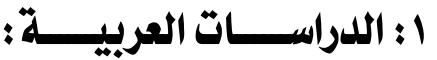

هدفت دراسة (العنزي، ب ( • ب) إلى التعرف على مدى نجاح مدير المدرسـة في تحقيق بيئة جاذبة لتعلم الطلاب في مدارس التعليم الثانوي والكثف عن الفروق بين آراء المعلمين تبعاً 
لبعض المتغيرات، واستخدم الباحث المنهج الوصفي الكمي والنوعي، وشملت عينة الدراسـة .

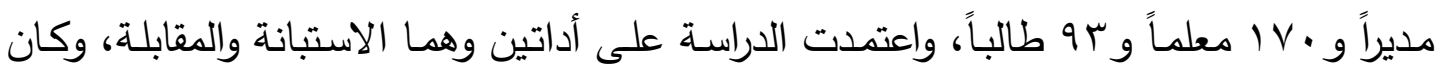
مـن أهم النتائج أن المديرين حققوا أدوارهم بدرجـة متوسطة في جميع المجالات، وكان أكثر

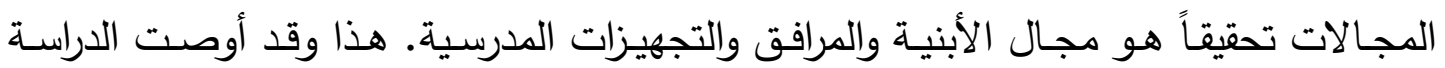
بضرورة توعية المجتمع والتربوين خاصة بأهمية البيئة الجاذبة وتأثيرها في تقدم التعليم.

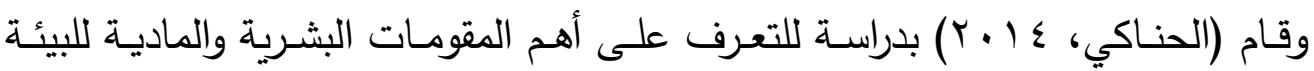
المدرسية الجاذبة للتعلم في المدارس الثانوية من وجهة نظر المعلمين والطلاب بمحافظة الرس، واستخدم الباحث المنهج الوصفي، واعتمد على الاستبانة كأداة لجمع البيانات، وتم اختيار العينة بطريقة عشوائية عنقودية وتكونت من فئتين الفئة الأولى 190 معلماً من معلمي المرحلة الثانوية

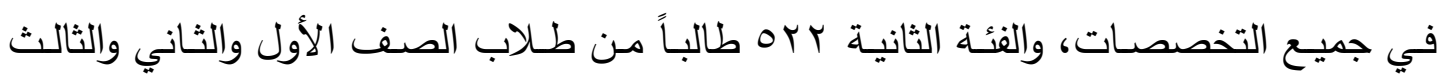
الثانوي بنين في المدارس النهاريـة الحكومية، وأوضحت الدراسـة أن للمقومات البشرية والماديـة للبيئة المدرسية الجاذبة للتعلم في المدارس الثانويـة أهميـة كبيرة جداً من وجهة نظر المعلمين والطلاب بمحافظة الرس.

وتتاولت دراسة (الخواجة، 0 ـ ـ ب) مشكلة غياب طلاب الصف الثالث الثانوي العام عن مدارسهح من حيث أسبابها وآثارهـا السلبية ومقترحات علاجها، كما استهدفت الدراسـة التعرف على مقومات البيئة المدرسية الجاذبة للتعلم في المدارس الثانوية العامة من وجهة نظر المعلمين والطلاب بمحافظة الغربية، واستخدم الباحث المنهج الوصفي، وتم استخدام الاستبانة في جمع

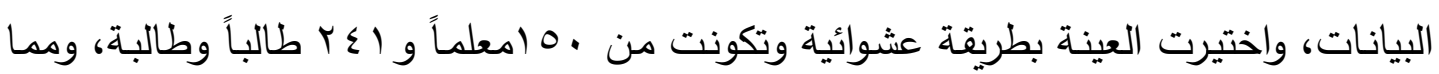
توصلت الدراسة أنه يمكن التغلب على مشكلة غياب الطلاب من خلال تواصل الإدارة المدرسية مـع أولياء الأمور وتوافر معلمين مؤهلين علمياً وتربوياً بالإضـافة إلى توافر حوافز تشجيعية للطلاب المتميزين دراسياً.

\section{ب : اللدراسات الأجنبية:}

قام Mitchelle (2004) بدراسـة استهدفت التعرف على العلاقات عبر الثقافيـة بين الطلاب في ست مدارس جاذبة من حيث ملاحظة السلوك وأنماط التفاعل واختيارت الدروس وتجمعـات الطـلاب وكذلك الفروق بين الطلبـة والطالبـات. وأشـارت الدراسـة إلى قدرة المدارس الجاذبة على إذابة الفروق بين الفصائل المختلفة حيث أظهرت النتائج حالة من التناغم بين 
الطلاب الأمريكيين والآسيويين والأفارقة والأوروبيين مع تفضيل الطلاب الأمريكيين التجمع مع الطي نظرائهم الآسيويين عن غيرهم من الأفارقة أو الأوروبيين، كما أظهرت النتائج أن الطالبات يملن الأنين الطين إلى تكوين مجموعات كبيرة أكثر من الطلبة.

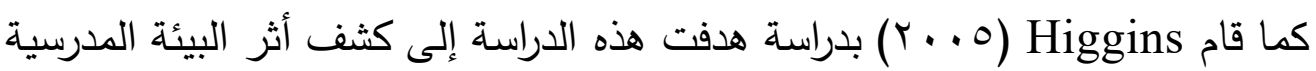

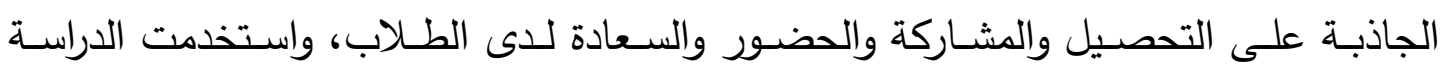

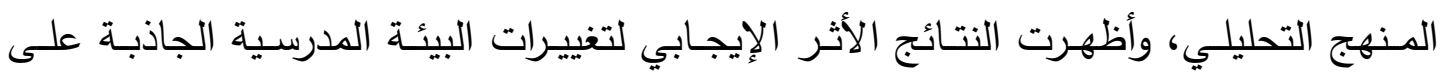

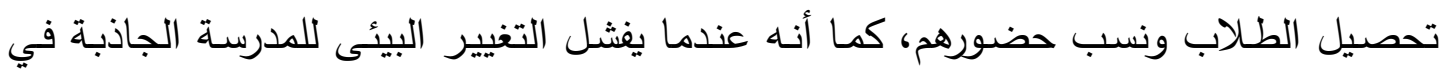
تغيير سلوك المعلم والمتعلم فذلك يكون بسبب عدم معالجة مشاكل الاتصال والتفاعل بين عناصر العملية التعليمية. - مائ. هذا وقد سعت دراسة Straus (2005 ) إلى إعادة بناء وهيكلة المدارس الجاذبة بهدف

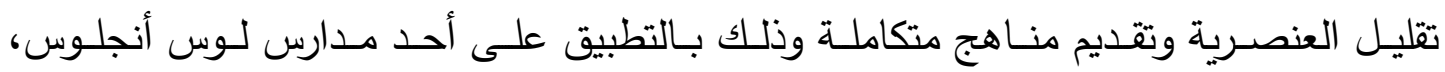

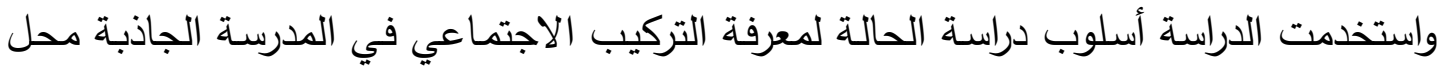

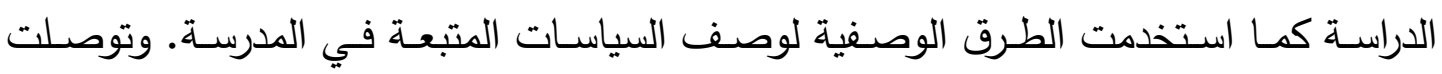
الدراسة إلى نموذج لإعادة بناء الدرسة بهدف تقليل العنصرية وتقديم مناهج متكاملة للطلاب. كما هدفت دراسـة Villarreal (2006 ) إلى مقارنـة تصورات المسؤولين عن المدارس

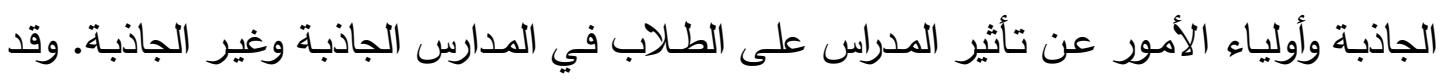

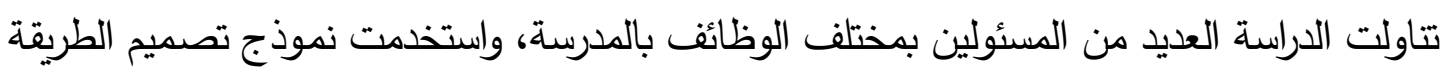
المختلطة كما استخدمت استبانة لجمع البيانات بالإضافة إلى المقابلات الشخصية، وشملت عين عينة الدراسة مجموعة من طلاب المدارس وأخرى من أولياء الأمور وعدد من الددرسين. وأسفرت نتائج

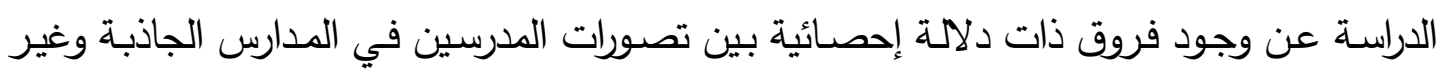

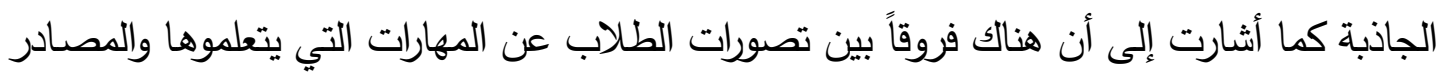
التعليمية المتوفرة وبالتالي تختلف خطة الطلاب لاستكمال دراستهم.

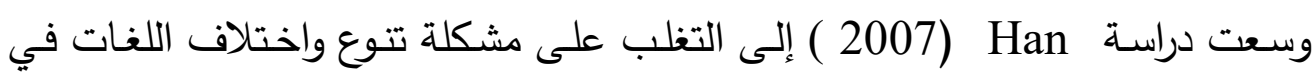

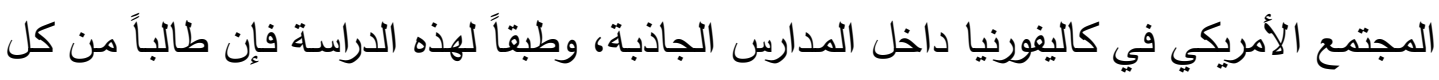

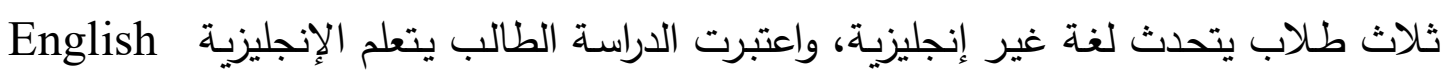
Learner 
الأساسية ( العلوم - الرياضيات - التكنولوجيا ) لهؤلاء الطلاب. وأوصت الدراسة بمجموعة من فئن

الاستراتيجيات في التعلم منها استراتيجية STS واستراتيجية ALLA واستراتيجية SCALE.

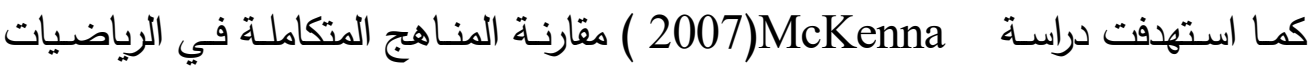
والعلوم والتكنولوجيا في المدارس الجاذبة في كاليفورنيا، واستخدمت منهج دراسة الحالة على أربعة

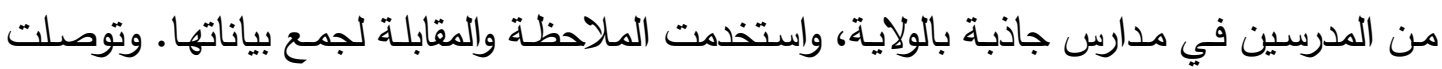
الدراسة إلى مؤشرات خاصة بتطوير المناهج المتكاملة في الرياضيات والعلوم والتكنولوجيا من خلال

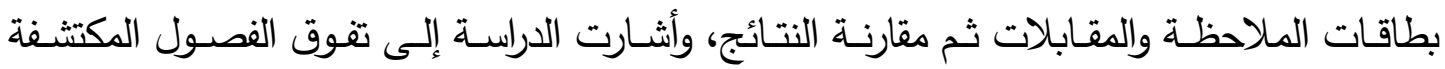
Discovery Classrooms في الددارس الجاذبة عن غيرها من الفصول.

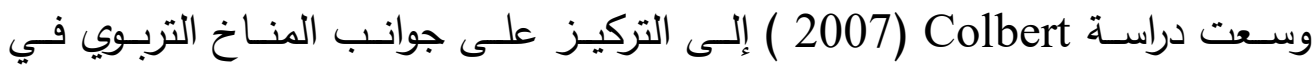

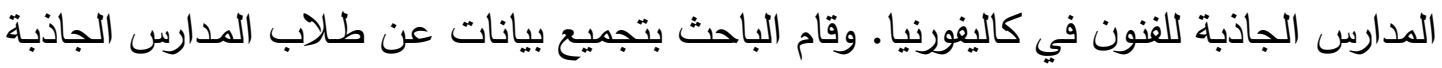

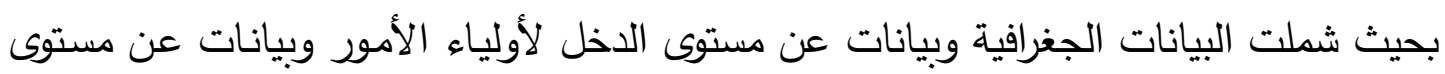

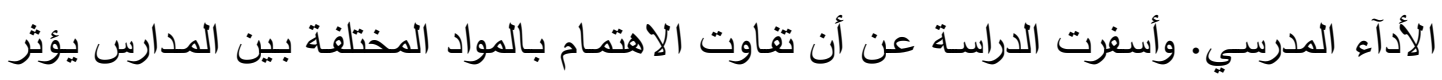

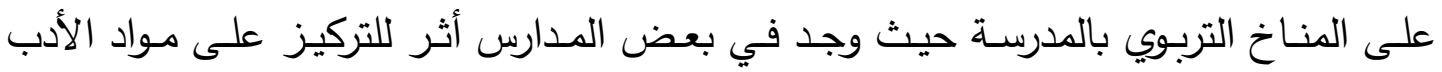

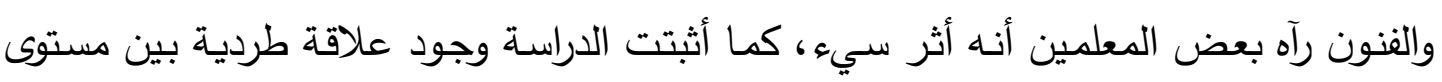

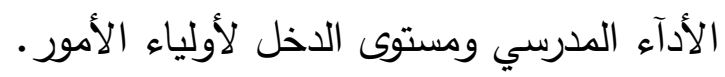
بينما هدفت دراسة Byamugisha (1 (1 • ب) إلى التعرف على مقومات البيئة الددرسية الجاذبة والمحفزة للتعلم بما تتضمنه من معلمين وإداريين وغرف صفية مريحة بالإضافة إلى توفير

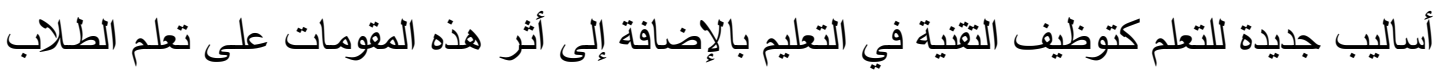

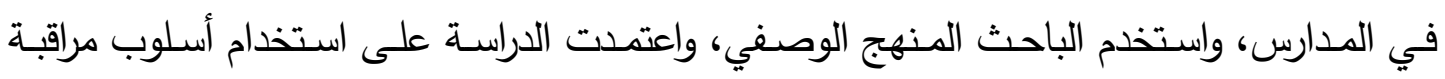

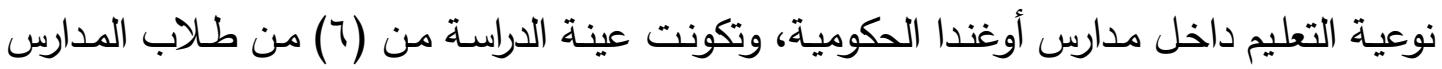
الابتدائية. وكان من أهم النتائج أن الطالب الذي يتناول الغذاء المناسب في المدرسة يكون تحصيله

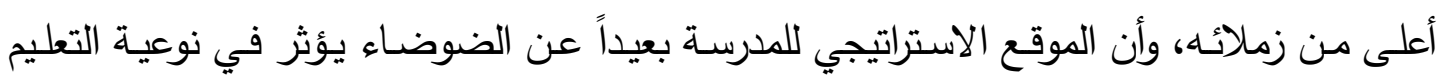

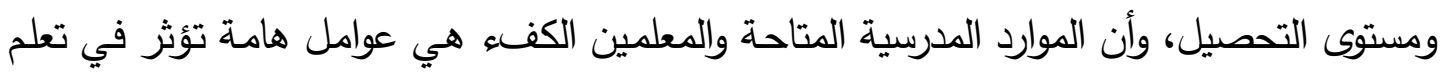
القراءة والرياضيات كما أن هناك عوامل إضافية أخرى في البيت والمدرسة.

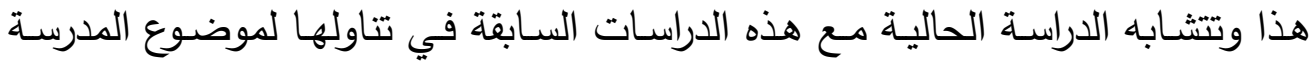

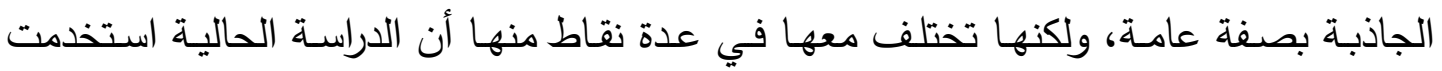


المنهج الوصفي وهي بذلك تختلف مـع بعض الدراسـات كدراسـة ( Higgins، 2005) التي تستخدم المنهج التحليلى، ودراسة ( Mckenna، 2007) التي استخدمت منهج دراسة الحالة. كما استخدمت الدراسة الحالية الاستبانة وهى بذلك تختلف عن بعض الدراسات التي استخدمت أدوات أخرى كدراسـة (Byamugisha، (2011) التي اسـتخدمت الملاحظــة لجمـع بياناتهـا، ودراسة (Mckenna، 2007) التي استخدمت الملاحظة وأسلوب المقابلة. ومن ناحية أخرى

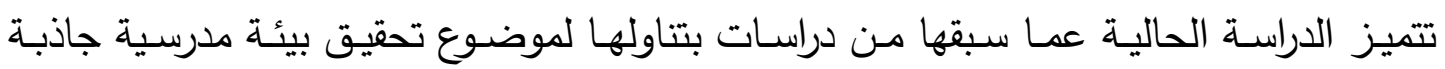
بمدارس الحلقة الثانية من التعليم الأساسي في حين تم التطبيق في معظم الدراسات السابقة

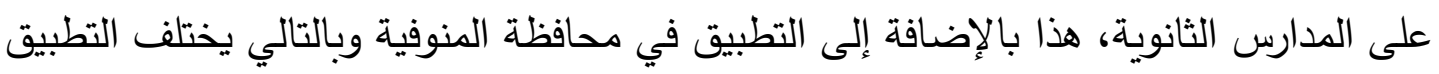
الميدانى عن باقى الدراسات الأخرى.

وقد استفادت الباحثة من الدراسـات السـابقة في التعرف على بعض نمـاذج المدارس

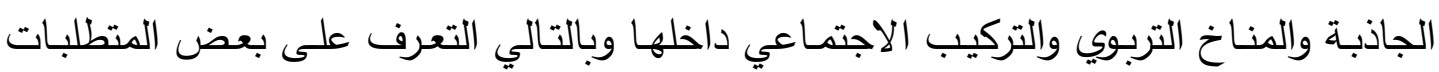

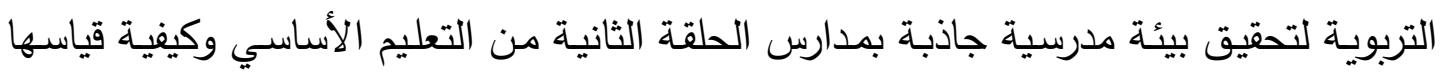

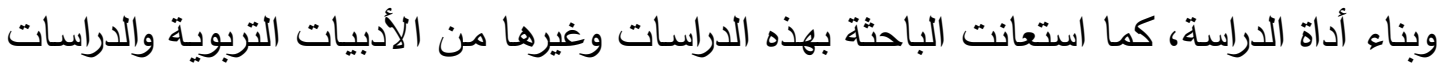
العلمية لمناقثة نتائج الدراسة الحالية وبناء التصور المقترح لتحقيق بيئة مدرسية جاذبة.

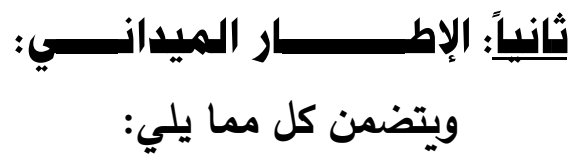

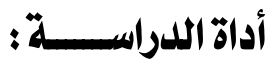

تم إعداد استبانة المنطلبات التربوية لتحقيق بيئة مدرسية جاذبة بمدارس الحلقة الثانية من التعليم الأساسي تتكون من جزئين هما:

\section{أ.البيانات الشفصية:}

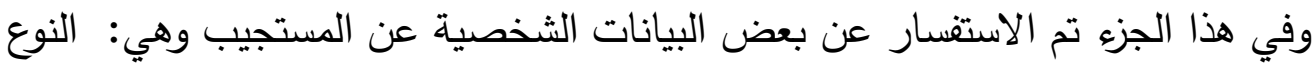

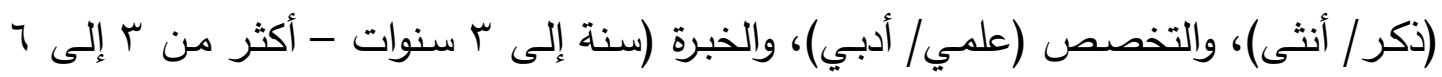

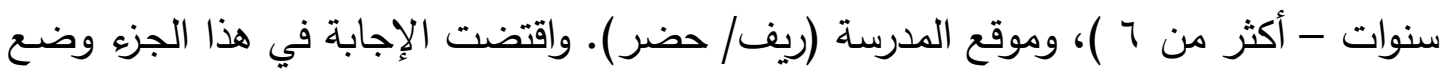
علامة ( ل) في المربع الذي يعبر عن إجابة المستجبيت. 


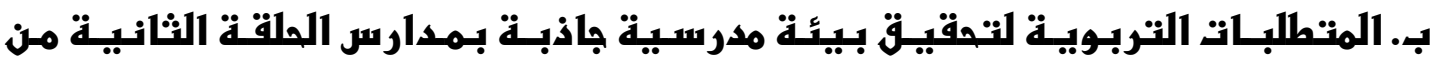

التعليم الأساسي:

وتـألف هــا الجـزيه مـن ثمانيــة محساور يتكـون كـل محسور مـن مجموعـة مـن

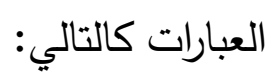

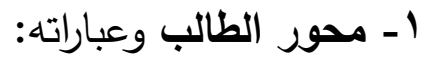

- - يتفاعل الطلاب مع التقنية الحديثة في المدرسة.

$$
\text { - - يسهم الطلاب في صناعة القرارات المدرسية. }
$$

- - يشارك الطلاب في ممارسة الأنشطة المدرسية المختلفة.

$$
\text { r- محور المعلم وعباراته: - يمارس الطلاب التعلم الذاتي. }
$$

- يتمكن المعلم من المادة العلمية في مجال تخصصه. - - يستخدم المعلم استراتيجيات التدريس والتقنيات الحديثة بغرفة الصف. - يساعد المعلم الطلاب على اكتساب مهارة التعلم الذاتي.

$$
\text { - - - يتمسك المعلم بأخلاقيات المهنة. }
$$

- - يتفرغ المعلم للعملية التعليمية ولا يتحمل أعباءً إدارية.

$$
\text { - - يدير المعلم الصف بفاعلية. }
$$

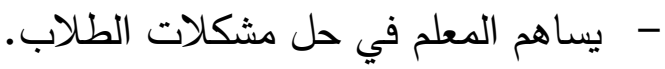

- - تسود روح التعاون بين المعلمين داخل المدرسة. - ت توافر لاى المعلم مهارات البحث العلمي.

$$
\text { r- محور المناهج وعباراته: }
$$

- - يراعي المنهج الفروق الفردية وحاجات الطلاب.

- - يراعي المنهج التكامل بين المواد الدراسية.

- - ينمي المنهج مهارات البحث العلمي عند الطلاب.

- - يشارك المعلمون في مناقشة مشكلات المنهج.

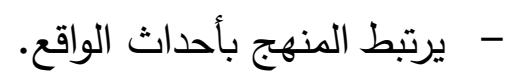

- - يتيح المنهج توظيف التقنيات الحديثة. 


\section{ع - محور طرق التدريس وعباراته:}

- تتوافر بالفصول الوسائل التعليمة المختلفة لتساعد على شرح المنهج. - تفعل طرق التدريس عملية التواصل مع الطلاب داخل وخارج المدرسة.

- تتوافر مصادر مختلفة للتعلم كالمكتبات ونادي التكنولوجيا. - تبوافر بالمعامل الأجهزة والأدوات المناسبة لشرح المنهج عملياً. هـ محور الأنثطة وعباراته:

- تفعل الأنشطة المدرسية بالمشاركة بين المعلمين والطلاب.

- تتنوع الأنشطة المدرسية مابين دينية وثقافية واجتماعية. - تتوزع الأنشطة الدرسية على المعلمين والمشرفين حسب تخصئ دائهاتهم واستعداداتهم. - يخص رائد نشاط متقرغ لتوزيع ومتابعة الأنشطة المدرسية. 7- محور المباني وعباراته: - - يتتاسب المبنى المدرسي ومرافقه مع أعداد الطلاب. - يراعي المبنى متطلبات تكنولوجيا التعليم داخل الفصول. - ت توافر بالمدرسة ملاعب لممارسة الأنشطة المختلفة. - - يوجد بالمدرسة معمل حاسب آلي مجهز ومفعل. - - توجد بالمدرسة قاعة للتربية الفنية مجهزة ومفعلة. - تتوافر بالدرسة دورات مياه صحية للطلاب. - - يوجد بالمدرسة مقصف أو صالة للطعام. - لمأل

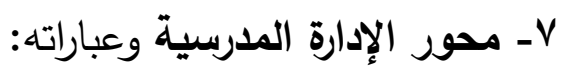

- تشرك إدارة المدرسة المعلمين في صناعة القرارات المدرسية. - تعزز الإدارة العلاقات الإنسانية بين أفراد المجتمع المدرسي. - تنفذ إدارة الددرسة دورات تدريبية لتطوير أداء المعلمين. - تمنح الإدارة حوافز تشجيعية للمتميزين من المعلمين والإداريين. - تراعي إدارة المدرسة قدرات الأفراد عند توزيع المسئوليات. - تتواصل إدارة المدرسة مع أولياء الأمور لحل مشكلات أبنائهم. - - تستخدم إدارة المدرسة التقنية الحديثة في الإدارة. 


\section{1- محور المشاركة المجتمعية وعباراته:}

- - يشارك المجتمع المحلي في رسم سياسة المدرسة وأهدافها التعليمية. - - يشارك أولياء الأمور المدرسة في شئونها ومناسباتها فكرياً واجتماعياً ومادياً. - - يشارك أولياء الأمور المدرسة في حل مشكلات أبنائهر. - تتوع مصادر تمويل المدرسة عبر المؤسسات غير الحكومية كالجمعيات الخيرية وغيرها. وتقتضي الاستجابة على هذه المحاور أن يضع المستجيب علامة ( ل) أمام كل عبارة

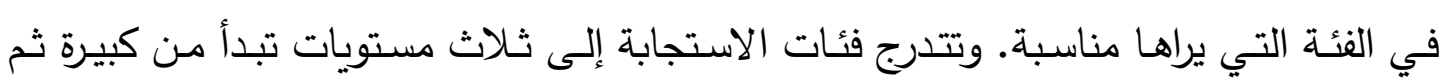
متوسطة ثم ضعيفة بأوزان نسبية (r-T - I ) على الترتيب.

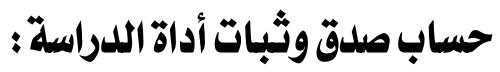

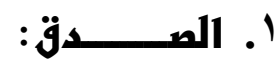

تم الوقوف على صدق الأداة باستخدام طريقة صدق المحكمين كما يلي:

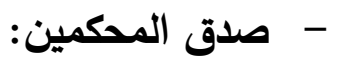
تم عرض الأداة على مجموعة من المحكمين من أساتذة التربية وعلم النفس وطلب منهم تحديد ملاحظاتهم حول مدى دقة عبارات محاور المتطلبات التربوية لتحقيق بيئة مدرسية جاذبة بمدارس الحلقة الثانية من التعليم الأساسي ومدى تمثيل هذه العبارات للمحاور التي تتنمي إليها

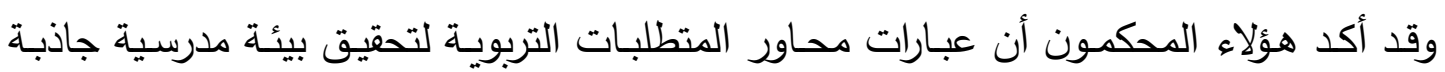

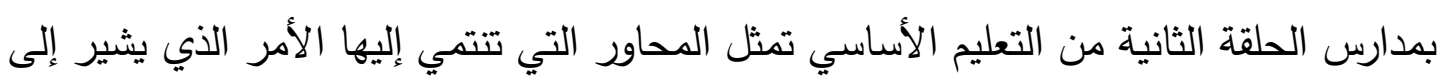

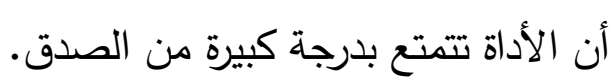

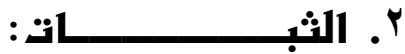

تم حسـاب ثبـات الأداة بتطبيقهـا على عينـة مكونــة مـن (0؛ ) معلمـاً مـن المـارس الحكومية بالحلقة الثانية من التعليم الأساسي بالمحافظة، ثم قامت الباحثة بإعادة تطبيق الأداة

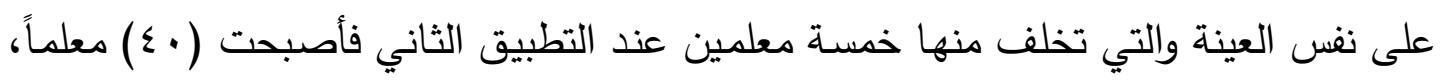

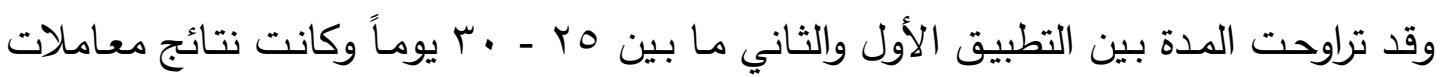
الارتباط كما يوضحها الجدول التالي رقم (1): 


\section{جلول (1) (- (1)}

"معاملات الارتباط بين التطبيق الأول والثاني على محاور المتطلبات التربوية لتحقيق بيئة مدرسية جاذبة بمدارس الحلقة الثانية من التعليه الأساسي

\begin{tabular}{|c|c|c|}
\hline 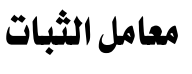 & محاور التتطلبات التربوية لتحقيق بيئة مدرسية جاذبة & ه \\
\hline$\cdot, \mathrm{VA}$ & محور الطالب & 1 \\
\hline$\cdot, \mathrm{vr}$ & محور المعله - مح & $r$ \\
\hline •, ro & محور المناهج & $r$ \\
\hline •, V4 & محور طرق التدريس & 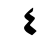 \\
\hline$\cdot, \wedge 1$ & محور الأنشطة & 0 \\
\hline$\cdot, v V$ & محور المباني & 7 \\
\hline$\cdot, \mathrm{rr}$ & محور الإدارة الملدرسية & $r$ \\
\hline$\cdot, 79$ & محور الشاركة المجتمعية & $\wedge$ \\
\hline
\end{tabular}

وجميع هذه المعاملات في الجدول رقم (1) دالة عند مستوى( ا ., ·) وهو ما يشير إلى أن الجزء الخاص بمحاور المتطلبات التربوية لتحقيق بيئة مدرسية جاذبة بمدارس الحلقة الثانية من التعليم الأساسي على درجة معقولة من الثبات.

\section{مجتمع وكينة الدراسة:}

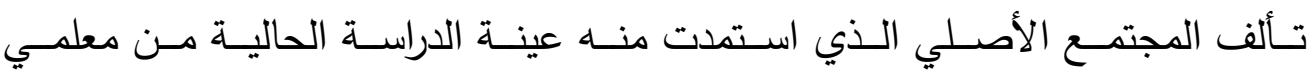
الهـدارس الحكوميـة بالحلقـة الثانيـة مـن التعليم الأساسـي بمحافظــة المنوفيـة وشــلت العينـة

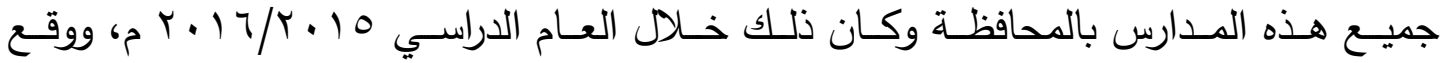

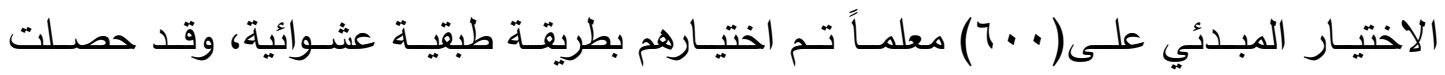

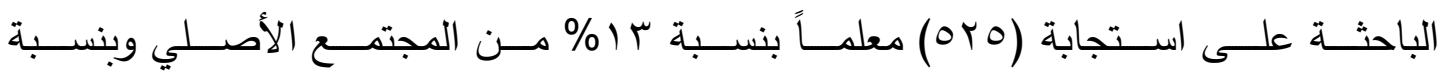

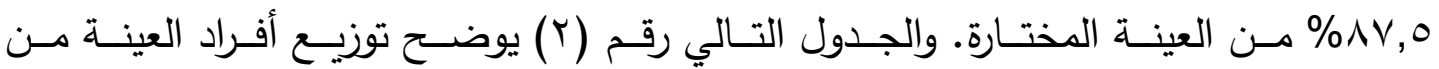
حيث النوع والتخصص والخبرة وموقع الدرسة. 


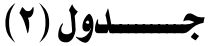

"خصائص عينة الدراسة وفقاً للنوع والتخصص وسنوات الخبرة وموقع المدرسة"

\begin{tabular}{|c|c|c|c|c|c|c|c|c|c|}
\hline \multicolumn{2}{|c|}{ موقع المدرسة } & \multicolumn{3}{|c|}{ سنوات الخبرة } & \multicolumn{2}{|c|}{ التخصص } & \multicolumn{2}{|c|}{ النوع } & \multirow[b]{2}{*}{ الفئات } \\
\hline الحضر & الريف & سنوات 7 أكثر من 7 & |إلى 7 سنو من بات & سنة إلى & أدبي & علمي & أنثى & ذكر & \\
\hline rAl & ris & irv & 171 & 14 . & rav & rOA & rrr & ror & العدد \\
\hline or,o & $\leqslant 7,0$ & $r r, r$ & rr & $r \varepsilon, r$ & $0 \cdot, 9$ & $\{9,1$ & 01,1 & $\{\Lambda, r$ & النسبة المئوية \\
\hline \multicolumn{2}{|c|}{ oro } & \multicolumn{3}{|c|}{ oro } & \multicolumn{2}{|c|}{ oro } & \multicolumn{2}{|c|}{ oro } & المجموع \\
\hline
\end{tabular}

\section{الأساليب الإحصائية المستخلمةة:}

تم اسـتخدام التكـرارات والنسـب المئويـة والمتوســات الحسـابية والانحرافـات المعياريـة

ومعاملات الارتباط، كما تم استخدام اختبار النسبة التائية T. Test لمعرفة دلالة الفروق بين المتوسطات الحسـابية لمحاور المتطلبات التربويـة لتحقيق بيئة مدرسية جاذبـة بمدارس الحلقـة الثانيـة مـن التعليم الأساسـي تبعـاً لكل من متغير التخصص (علمي - أدبـي) ومتغير موقع

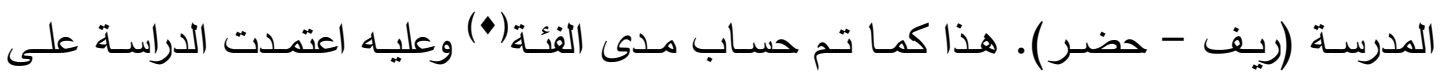
المعايير الإحصائية المبينة بالجدول التالي رقم (ب):

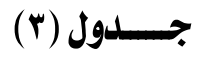

"المعايير الإحصائية للدراسة"

\begin{tabular}{|c|c|c|}
\hline \multicolumn{2}{|c|}{ المــــلـى } & قوة العبارة \\
\hline إلى & من & \\
\hline 1,79 & 1 & ضميفة \\
\hline$r, r r$ & $1,7 v$ & متوسطة \\
\hline$r$ & $r, r \varepsilon$ & كبيرة \\
\hline
\end{tabular}

تطبيق أداة الدراسة:

تم تطبيق الأداة على أفراد العينة بكل مدرسة وشرح الغرض من تطبيقها وأهدافها وكيفية الاستجابة عليها والوعد بالمحافظة على سرية الاستجابة ثم جمع الأداة من المعلمين. 


\section{نتائج الجانب الميلاني للدراسة ومناقشتها :}

أسفر التحليل الإحصائي للبيانات والمعلومات التي تم الحصول عليهائا من تطبيق أداة

$$
\text { الدراسة على أفراد العينة عن النتائج التالية: }
$$

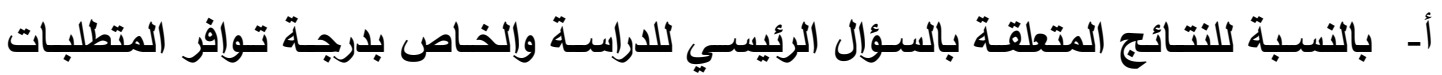

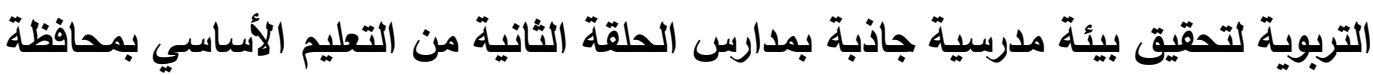

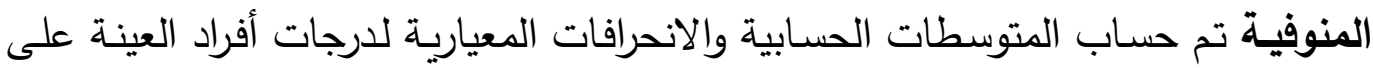
محاور المتطلبات التربويـة لتحقيق بيئة مدرسية جاذبة بمدارس الحلقة الثانية من التعليم الأساسي وكانت النتائج كما يوضحها الجدول التالي رقم (ع ):

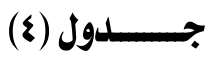
"المتوسطات الحسابية والانحرافات الميارية لمحاور المتطلبات التربوية لتحقيق بيئة ملدرسية جاذبة بمدارس

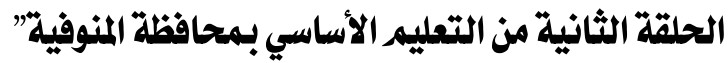

\begin{tabular}{|c|c|c|c|c|c|}
\hline الترتيب & المتوسط النسبي" & الالنحراف & الحسابي & | العبارات & المدحـــــــــــور \\
\hline 1 & $r, \cdot r$ & $1, r q$ & A, Ir & $\xi$ & محور الطالب \\
\hline r & $1, \wedge \Lambda$ & $r, r Y$ & 19,94 & 9 & محور المعله \\
\hline$\xi$ & $1,\{r$ & $r, 7 \Lambda$ & 1,07 & 9 & محور المناهج \\
\hline$r$ & $1, r 1$ & $1, v \cdot$ & $\bar{\varepsilon}, \wedge \varepsilon$ & $\xi$ & محورطرق التدريس \\
\hline$r$ & 1,0r & 1,11 & 9,14 & $\xi$ & محور الأنشطة \\
\hline 0 & $1, r \wedge$ & r,07 & $9, Y r$ & $r$ & محور المباني \\
\hline 7 & $1, \mathrm{rA}$ & $r, \$ 7$ & $9,+r$ & $r$ & محور الإدارة المدرسية \\
\hline \multirow[t]{2}{*}{$\wedge$} & 1,19 & 1,11 & $\xi, \vee \wedge$ & $\xi$ & محور المشاركة المجتمعية \\
\hline & 1,01 & 17,74 & $T A, I T$ & so & المجموع \\
\hline
\end{tabular}

يتضح من الجدول السابق رقم (ع) أن المتطلبات التربوية لتحقيق بيئة مدرسية جانبة

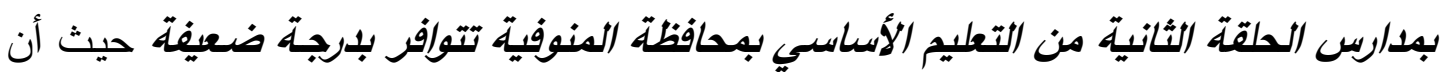

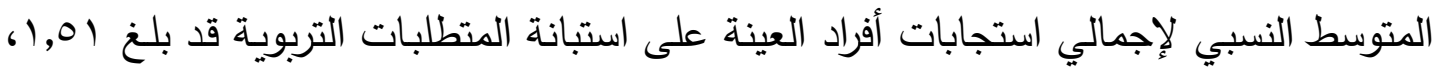


ومقارنة بالمعايير (•) التي اعتمدت عليها الدراسة الحالية يتضح أنها تقع في المستوى ضعيف والذي يمتد مداه من 1 إلى 17 , 1 مما يشير إلى الضعف في في مستوى توافر المتطلبات التربوية

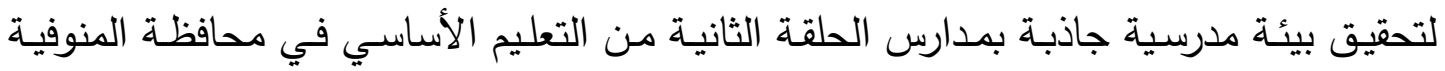
بصفة عامة.

ويمكن تفسير هذا الضعف في مستوى توافر المتطلبات التربوية لتحقيق بيئة ددرسية

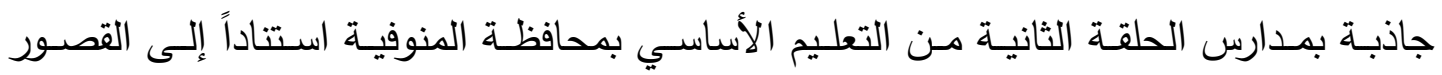

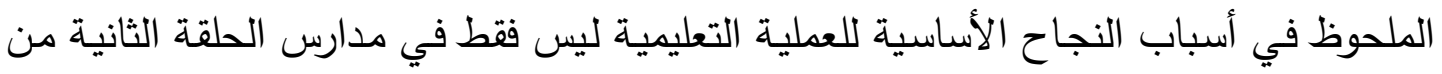
التعليم الأساسي أو في هذه المحافظة بل في جميع المراحل التعليمية وفي ربوع مصر كلها. وتتلخص هذه الأسباب في ثلاث نقاط وضحها بان كي مون الأمين العام للأمم المتحدة في

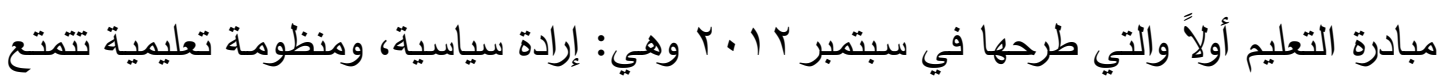

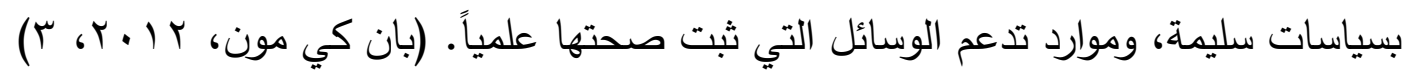

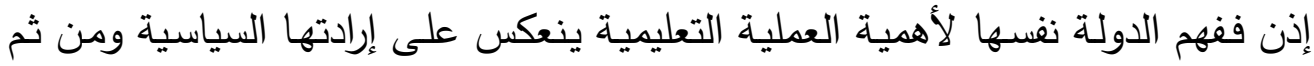

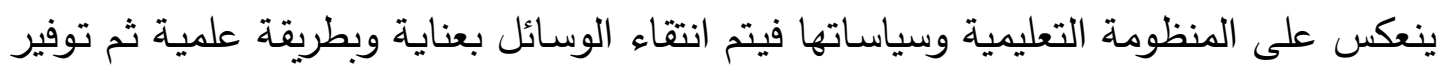

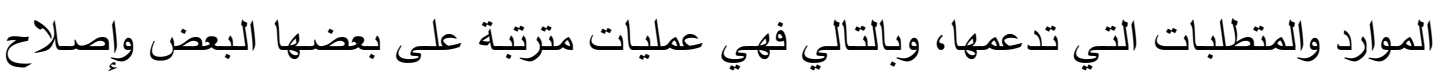

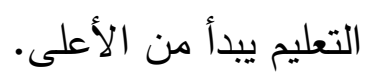

ويؤكد هذه النتيجة مـا نشر في اليوم السـابع نقلاً عن تقرير الجهاز المركزي للتعبئة

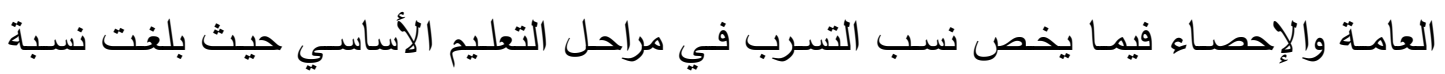

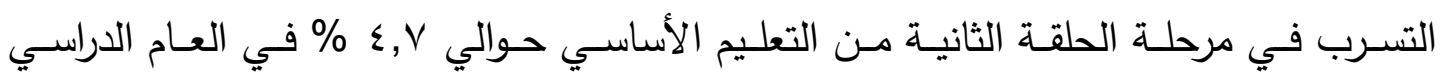

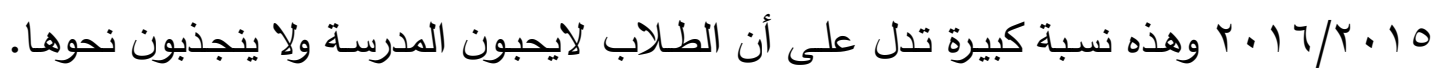

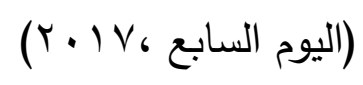

كما يمكن إرجاع الضعف في مستوى توفر المتطلبات التربويـة لتحقيق بيئة مدرسية

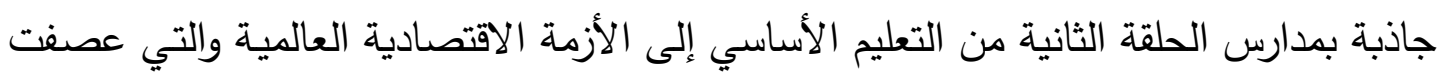

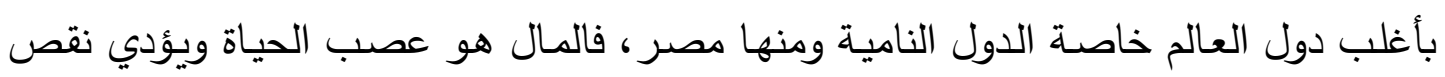
الإنفاق على التعليم في مصر إلى نقص الكثير من متطلبات البيئة المدرسية الجاذبة فنسبة

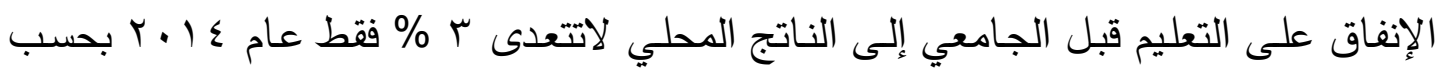




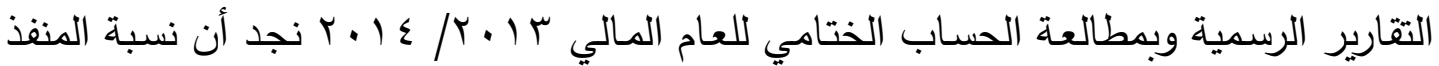

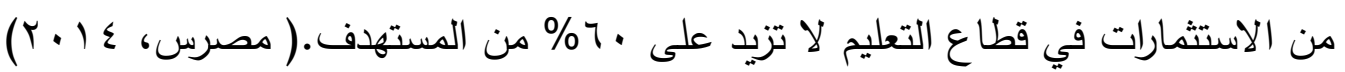
وعلى صعيد آخر يمكن تفسير ضعف مستوى توفر المتطلبات التربوية لتحقيق بيئة

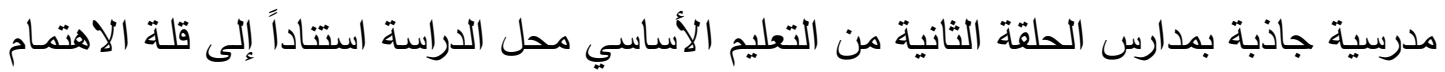

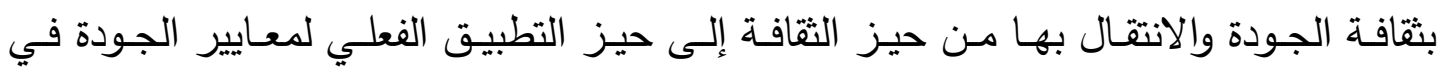
المؤسسـات التعليميـة في مصر والذي يضـمن توفير منطلبـات البيئة الددرسية الجاذبـة. فقد

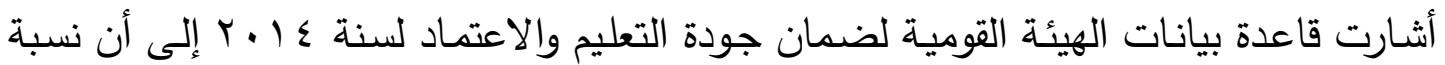

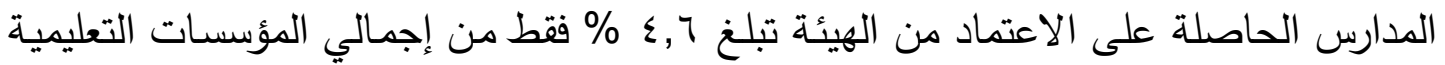

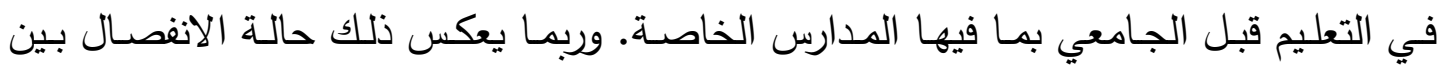
المعرفة والتطبيق بمعنى أن هناك فرق كبير بين ثقافة الجودة وتطبيق الجودة وتوفير متطلباتها فالثقافة تقف عند حدود المعرفة فقط، وبالفعل نجد أن هناك العديد من الدورات تعقد، والعديد

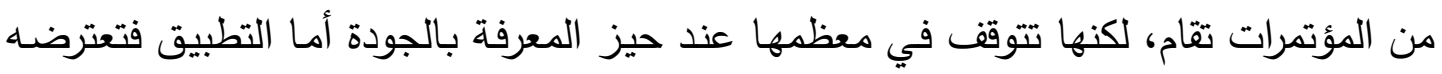

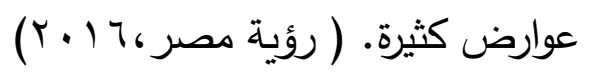

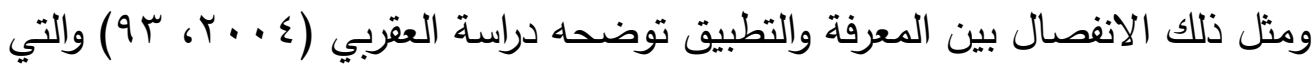

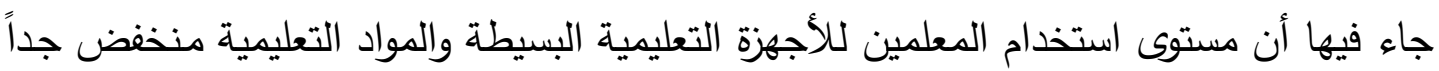
مقارنة بمعرفتهم بها.

كما يتضح من الجدول السابق رقم (؟) أن محور الطالب هو المحور الأعلى من بين

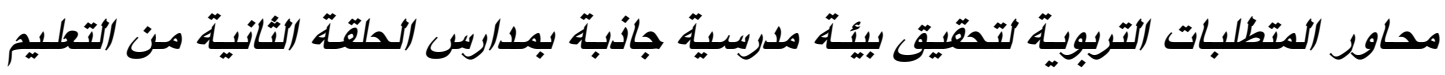

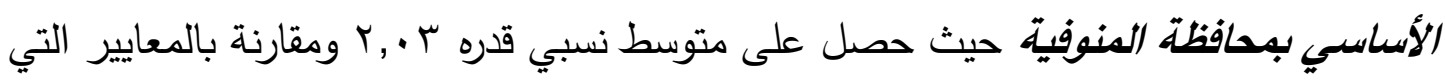

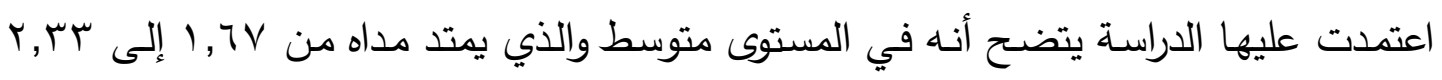
وهذا يعني توافر تلك المتطلبات التربوية الخاصة بمحور الطالب بدرجة متوسطة بمدارس الحلقة الثانية من التعليم الأساسي بمحافظة المنوفية.

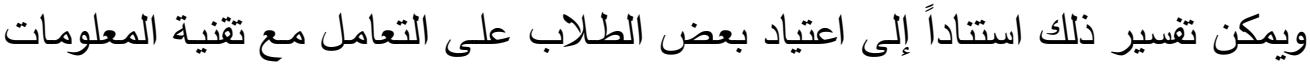

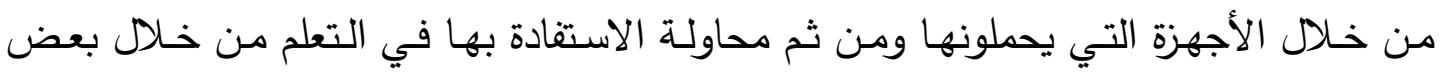

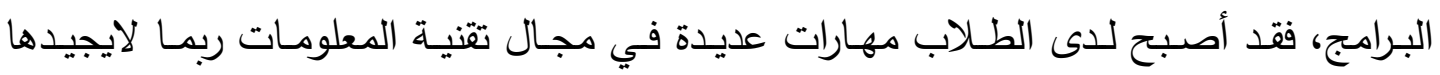

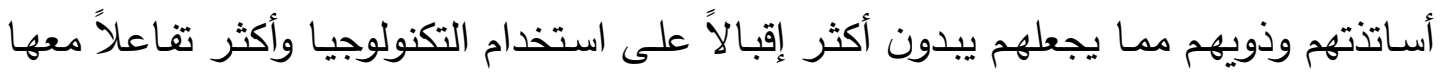
متى ما أتاحت المدرسة لهم ذلك ولو بقدر ضئيل. 
وجدير بالذكر وتبعًا لما تقوله دكتورة مارتا ستون، مدير مركز تكنولوجيا التعليم بكلية هارفارد لدراسات التربية والتعليم العليا، فإن إحدى المشكلات الدائمة في مجال تكنولوجيا التعليم

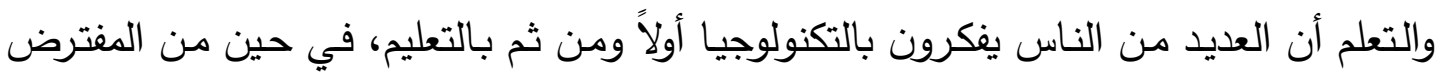
التركيز على التعليم أولاً ثم تدعيمه بما يناسب ويخدم لعملية التعليمية من أدوات التكنولوجيا.

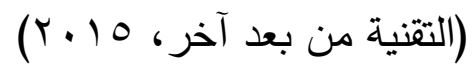

هذا كما يمكن تفسير كون المتوسط النسبي لمحور الطلاب جاء في المستوى متوسط

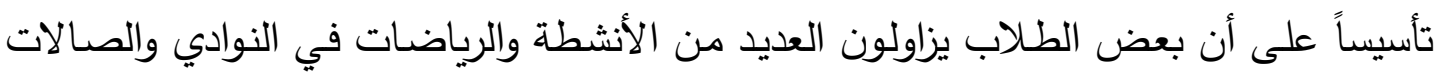

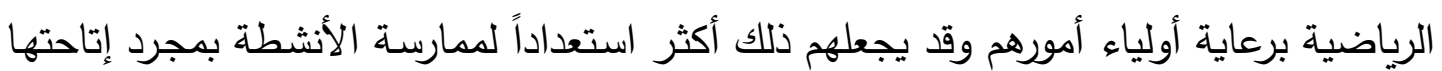
بالمدرسة ولو لمرات معدودة وبإمكانيات محدودة جداً.

ومن جانب آخر يتضح من الجدول السابق رقم (ع)أن محور المشاركة المجتمعية هو المحور الأدنى من بين محاور المتطلبات التربوية لتحقيق بيئة مدرسية جانبة بدارس لهن الحلقة الثانية من التعليم الأساسي بدحافظة المنوفية حيث حصل على متوسط نسبي قدره

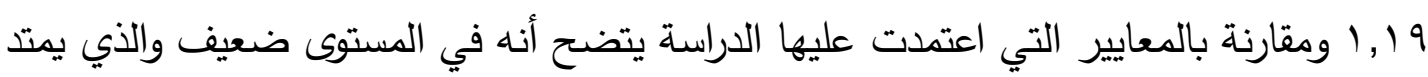

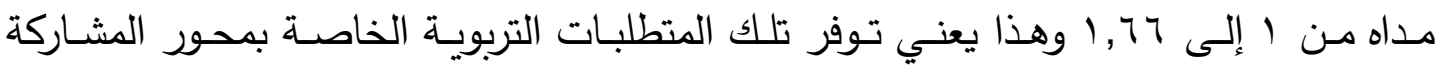
المجتمعية بدرجة ضعيفة في مدارس الحلقة الثانية من التعليم الأساسي بمحافظة المنوفية.

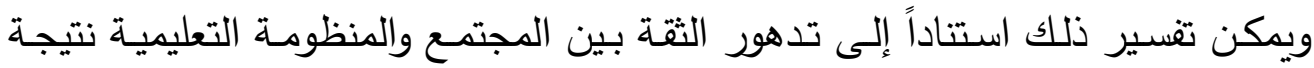
لضعف جودة خدمات التربية والتعليم الدقدمة في المدارس، بالإضافة إلى ضعف الصلة بين

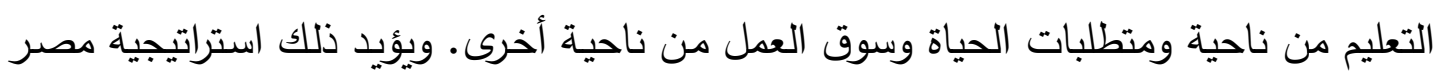

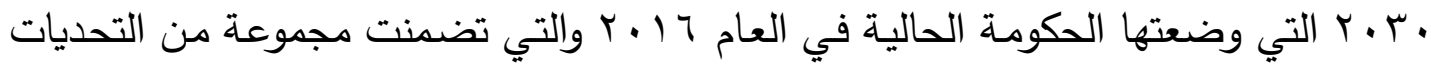

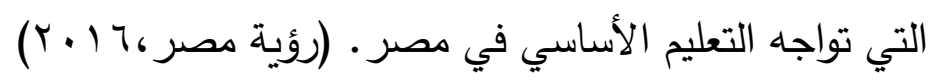

وتدهور الثقة بين المجتمع والمنظومة التعليمية وضعف الصلة بين التعليم ومتطلبات الحياة وسوق العمل يؤدي إلى تقاعس رجال الأعمال والمستثمرين والجمعيات الأهلية والمجتمع المحلي ككل عن آداء أدوارهم في المشاركة في رسم السياسات التعليمية وتقديم الدعم المالي وتوفير المتطلبات التربوية لتحقيق بيئة مدرسية جاذبة وكل ذلك يؤثر في النهاية على مصلحة العملية التعليمية في مصر . 

ب- أما بالنسبة للنتائج المتعلقة بالسؤالين الفرعيين في الدراسة فهي كالتالي: 1 - النتائج الخاصة بأثر متغيرات (التخصص - مكان المدرسة) على مستوى توافر المتطلبات

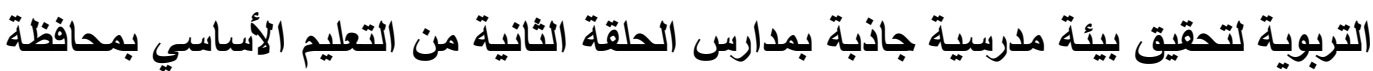

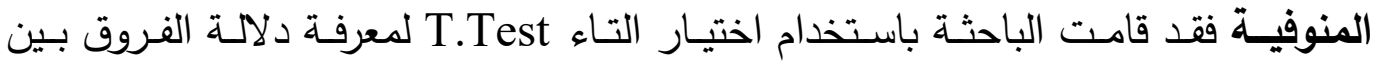
المتوسطات الحسابية للمحاور الثمانية للمتطلبات تبعاً لكل من متغير (التخصص - مكان

$$
\text { المدرسة). وقد أسفرت النتائج عما يلي: }
$$

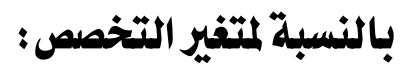

يوضح الجدول التالي رقم (0) الفروق بين المتوسطات الحسابية لمحاور المتطلبات

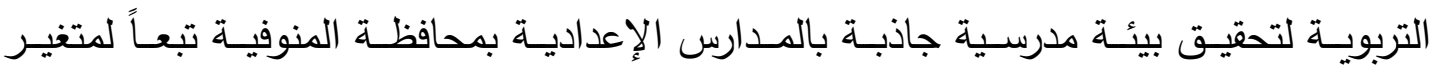
التخصص باستخدام اختبار التاء T.Test:

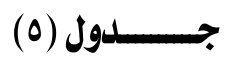

"قيم "ت” للالالة الفروق بين متوسطات محاور المتطلبات التزبوية لتحقيق بيئة مدرسية جاذبة بمدارس الحلقة

\begin{tabular}{|c|c|c|c|c|c|c|}
\hline \multirow{2}{*}{ مستوى الدلالة } & \multirow{2}{*}{ "قيمة } & \multicolumn{2}{|c|}{ أدبي ذ = rYV } & \multicolumn{2}{|c|}{ علمي ن = علي } & \multirow[t]{2}{*}{ التخصص } \\
\hline & & الالمياري & المتوسط & الانحراف & المتوسط & \\
\hline \multirow{4}{*}{$\frac{2}{7}$} & r, 97 & $1, r)$ & $\vee, 97$ & $1, r \varepsilon$ & $\Lambda, r q$ & محور الطالب \\
\hline & $\{,\{9$ & $r, r r$ & $17,\{9$ & r,ir & IV,rV & محور المعلد \\
\hline & $\boldsymbol{r}, \mathfrak{\xi \xi}$ & $r, r q$ & $\Lambda, \cdot 1$ & $\xi$ & $9,1 r$ & محور المناهج \\
\hline & $r, 70$ & $1, r^{\prime}$ & $\xi, O \gamma$ & $r, \bullet V$ & $0,1 r$ & محور طرق التدريس \\
\hline \multirow{4}{*}{ th } & $1, \cdot \xi$ & I,AT & $7, \cdot \bullet$ & 1,90 & $7, r r$ & محور الأنشطة \\
\hline & 1,19 & $r, r \varepsilon$ & 9,01 & r,Yq & 9,94 & محور المباني \\
\hline & $1, r v$ & $r, r q$ & $\wedge, \wedge \wedge$ & $r, 71$ & 9,17 & محور الإدارة المدرسية \\
\hline & $1, A v$ & $1, \bullet r$ & $\xi, 7 \uparrow$ & $1, r q$ & $\xi, \wedge \wedge$ & محور المشاركة المجتمعية \\
\hline دالة & r,OV & 1•,Ar & 77,19 & $1 \xi, 0$ & $v \cdot, 11$ & المجموع \\
\hline
\end{tabular}

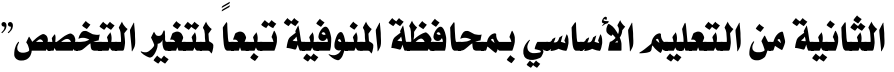




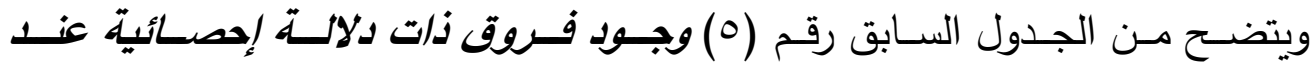

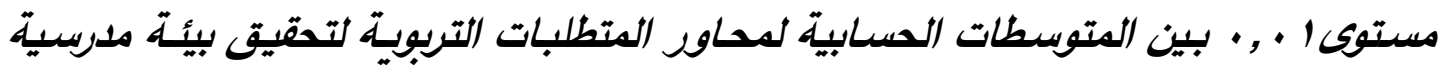
جانبة بدارس الحلقة الثانية من التعليم الأساسي بدحافظة المنوفية تبعاً لمتغير التخصص

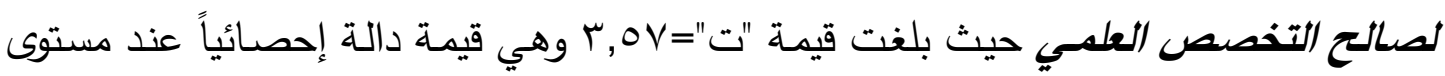

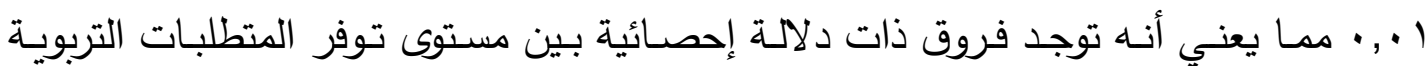
لتحقيق بيئة مدرسية جاذبة بددارس الحلقة الثانية من التعليم الأساسي بمحافظة المنوفية كما يراها معلموا التخصصات العلمية وبين زملائهم من معلمي التخصصات الأدبية لصالح معلمي

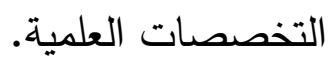

وربما يرجع ذلك إلى طبيعة المواد العلمية التي يدرسها معلموا التخصصـات العلميـة والتي تحتم وجود أدوات وأجهزة معينة تضطر المدرسة إلى توفيرها لتيسير عملية الثرح للطلاب بعكس المواد الأدبية التي لاتهتم المدرسة بتوفير أدوات تعين على شرحها بالرغم من أهميتها إلا أن الاهتمام ينصب على المواد العلمية خاصة في ظل قلة الموارد بالمدارس. وحتى على المستوى الاجتماعي نجد أن المجتمع متمثلاً في أولياء الامور مثلاً يولي اهتماماً بدراسة المواد العلمية أكثر من المواد الأدبية لذا قد تجد ولي أمر يثكو من قلة تحصيل

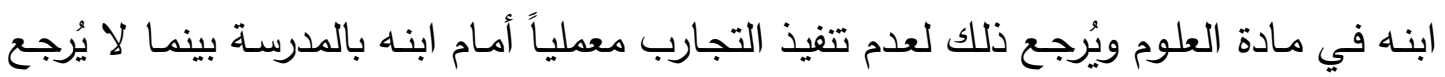
ضعف تحصيل ابنه في مادة الجغرافيا لعدم وجود خريطة العالم أو عدم وجود أفلاماً علمية تعرض تضـاريس سطح الأرض. وبـالطبع إن هي إلا قسمة ضـيزى وتقدير خـاطيء لأهميـة العلوم الأدبية لكنها ثقافة مجتمع تحتاج إلى زمن طويل حتى تتغير .

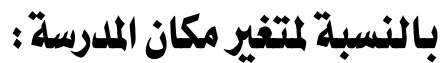

يوضـح الجدول التالي رقم (؟) الفروق بين المتوسطات الحسابية لدحاور المتطلبات التربوية لتحقيق بيئة مدرسية جاذبة بمدارس الحلقة الثانية من التعليم الأساسي بمحافظة المنوفية تبعاً لمتغير مكان الددرسة باستخدام اختبار التاء T.Test: 


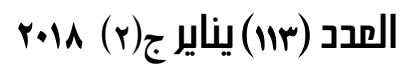

مجلة كلية التربية ببنها

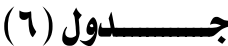

"قيم "ت" لدلالة الفروق بين متوسطات محاور المتطلبات التربوية لتحقيق بيئة مدرسية جاذبة بمدارس الحلقة

الثانية من التعليم الأساسي بمحافظة المنوفية تبعاً لتففير مكان المدرسة"

\begin{tabular}{|c|c|c|c|c|c|c|}
\hline \multirow{2}{*}{ مستوى } & \multirow{2}{*}{ "قيمة } & \multicolumn{2}{|c|}{ حضر ذ = حيl } & \multicolumn{2}{|c|}{ ريف ن= } & \multirow{2}{*}{ مكان الملدرسة } \\
\hline & & الالمياري & المتوسط & الالمياري & المتوسط & \\
\hline \multirow{2}{*}{$\frac{2}{5}$} & $r, 01$ & $1, r \varepsilon$ & $\vee, १ \xi$ & 1,19 & $\Lambda, r \xi$ & محور الطالب \\
\hline & $\xi, \xi r$ & $r, 19$ & 17, or & r, rA & $\mid V, r \wedge$ & محور المعله \\
\hline \multirow{7}{*}{$\int_{2}^{-1}$} & $1, Y r-$ & $\mathrm{r}, \wedge \wedge$ & $\Lambda, \mathrm{V}$ & r,Zr & $\Lambda, r \xi$ & محور المناهج \\
\hline & $\cdot, 97-$ & $1,7 r$ & $\{, 91$ & $1, \mathrm{rq}$ & $\varepsilon, \vee\urcorner$ & محور طرق التدريس \\
\hline & •, $\{\wedge$ & 1,90 & $7, \cdot 9$ & $1, A 1$ & $7,1 v$ & محور الأنشطة \\
\hline & $r, 11-$ & $r, r$. & 9,94 & $r, r v$ & $9, \xi \vee$ & محور المباني \\
\hline & $1,19-$ & r,or & $9,1 \varepsilon$ & r, rA & $\wedge, \wedge \wedge$ & محور الإدارة المدرسية \\
\hline & $\cdot, 11$ & $1, r 1$ & $\xi, \vee \vee$ & 1,17 & $\varepsilon, \vee q$ & محور المشاركة المجتمعية \\
\hline & $\bullet, \bullet$ & Ir, Y & $7 \Lambda, \cdot 1$ & 11,91 & 71,17 & المجموع \\
\hline
\end{tabular}

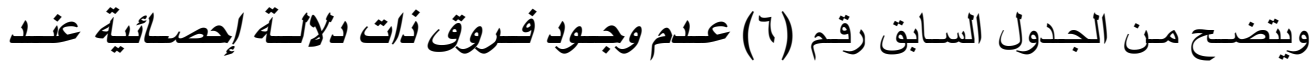

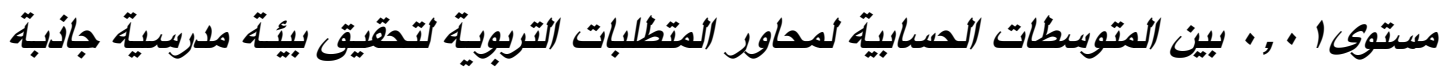

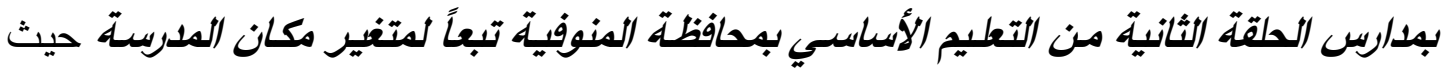

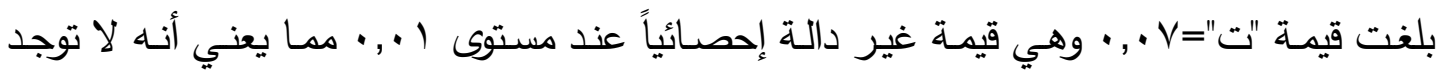
فروق ذات دلالة إحصائية بين مستوى توفر المتطلبات التزبوية لتحقيق بيئة مدرسية جاذبة بمدارس

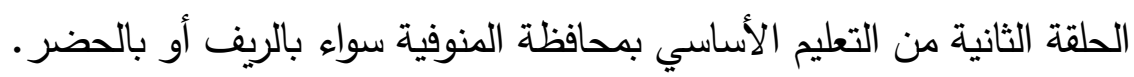

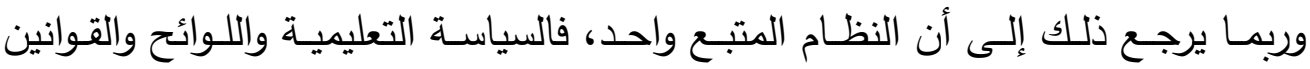

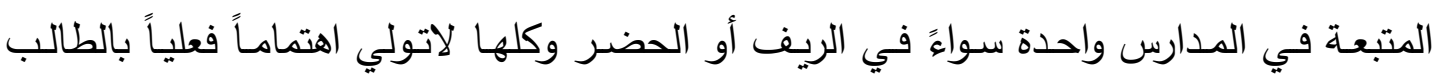

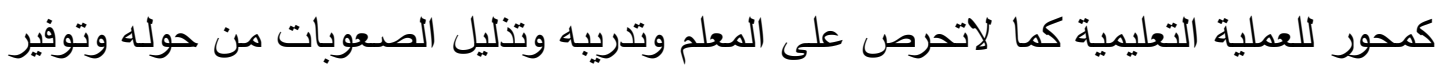
كافة المتطلبات التربوية من أجل بيئة تعليمية جاذبة.

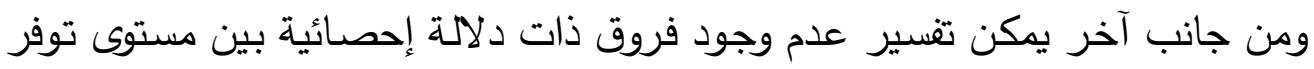

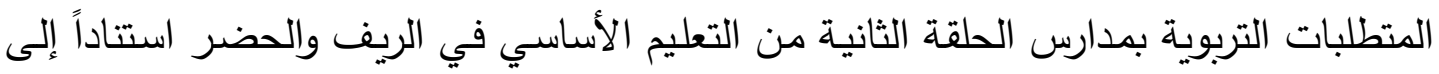

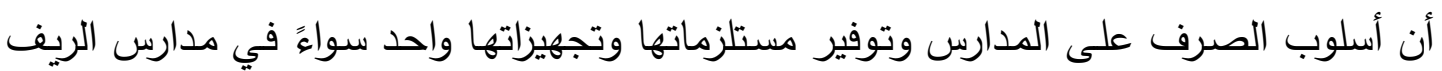


أو الحضر، ونظراً لضعف ميزانية التعليم بشكل عام فإن أسلوب الصرف على المدارس دائماً

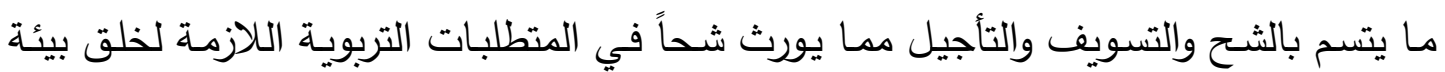

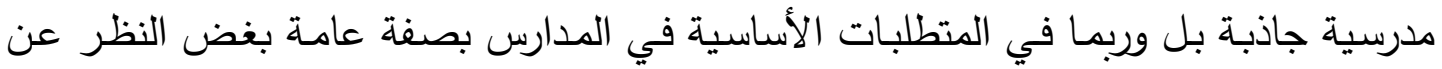

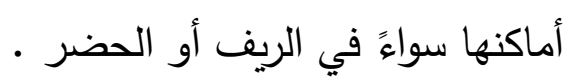

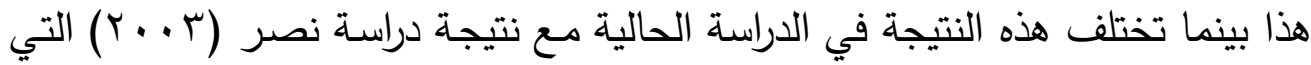

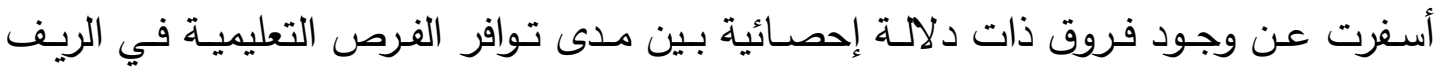

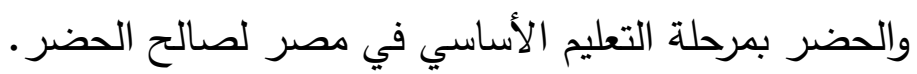

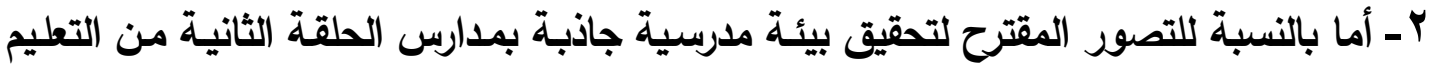

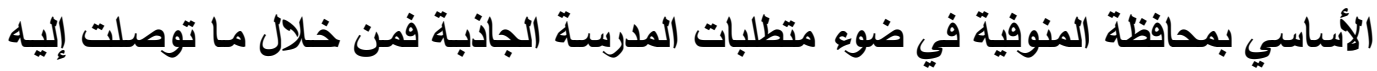

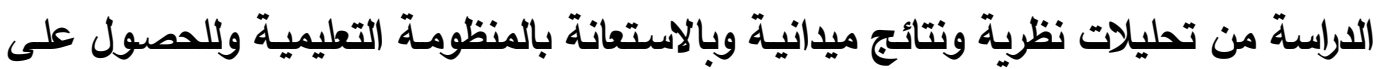
مخرجات تعليمية جيدة قدمت الباحثة التصور التالي ويتكون من ثلاثة عناصر :

\section{أولاً : التخطيط للبيئة المدرسية الجاذبة:}

وتتم عملية التخطيط وفقاً لهذا التصور بما يلي: التئية

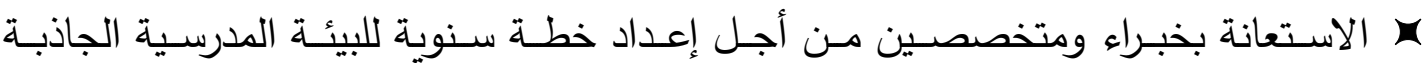
والإشراف على تتفيذها وتقويمها. × تحديد الأهداف والمعايير الأساسية للبيئة المدرسية الجاذبة بما يتتاسب وحاجات المعلمين

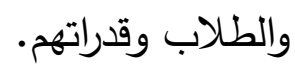
× تحديد إجراءات ومواعيد تنفيذ المخطط وكذلك تحديد أساليب تقويمه ومتابعته بحيث تكون في متناول المعلمين والطلاب المقرر التحاقهم بالمدرسة الجاذبة.

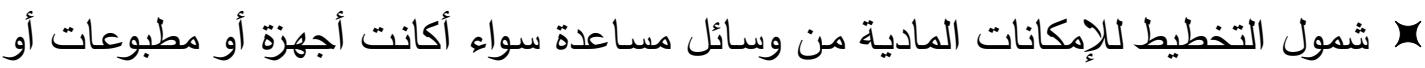
إمكانات بشرية لتقديم التسهيلات اللازمة للبيئة المدرسية الجاذبة. ويستد نظام البيئة المدرسية الجاذبة على عدد من الأسس والمعايير منها ترابط عناصر منظومة البيئة المدرسية الجاذبة واتساقها وتكامل جهود المعلمين والطلاب السابقة واللاحقة وجودتها. ويكون لهذه الخطة مجموعة من المخرجات المتوقعة والملموسة تتمثل في تقليل نسب

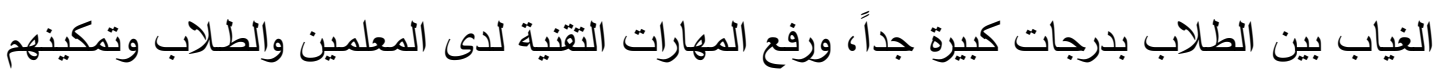
من مواكبة التطورات المعاصرة، وتتمية مهارة التعلم الذاتي لدى الطلاب بالإضافة إلى اكتساب لئل المعلمين والطلاب فن التعامل مع الناس وخلق روح التعاون بينهم. 


\section{ثانياً : آليات تنفيذوتحقيق البيئة المدرسية الجاذبة :}

وهي مجموعـة من الآليـات والإجراءات لكل محسور مـن محساور المتطلبـات التربويـة الثمانية بالدراسة وهي كالتالي:

1- آليات توفير المتطلبات التربوية الخاصة بالمعلم:

يمكن توفير المتطلبات الخاصة بالمعلم بالاعتماد على الإجراءات التالية:

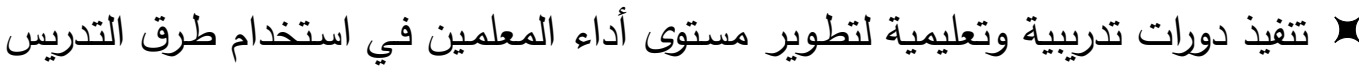
الحديثة وإدارة الفصل والتعامل مع الموهوبين. × عقد ندوات وورش تتناول موضوعات مختلفة في كافة نواحي العملية التعليمية.

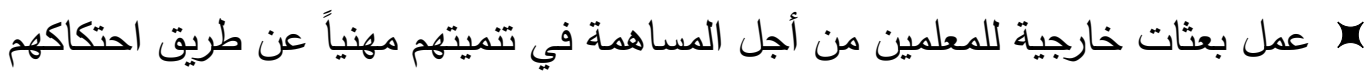
بخبرات أجنبية. (1) منح حوافز لتشجيع المعلمين على الابتكار والإبداع في الأداء. r- آليات توفير المتطلبات التربوية الفاصة بالإدارة:

يمكن توفير المتطلبات الخاصة بالإدارة بالاعتماد على الإجراءات التالية:

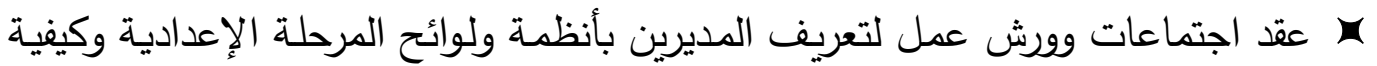
إدارة المواقف التعليمية وصناعة القرار التعليمي. جـ إنشاء وحدة المدرسة الجاذبة على غرار وحدة التدربب داخل كل مدرسة.

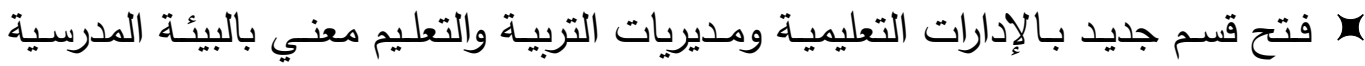
الجاذبة ويكون له مشرفون متخصصون يتابعون المدارس في هذا الثأن.

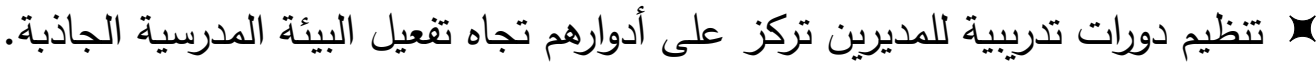
"دمآليات توفير المتطلبات التربوية الفاصة بالمنهج:

يمكن توفير المتطلبات الخاصة بالمنهج بالاعتماد على الإجراءات التالية: الاستفادة من التخذيـة الراجعة التي يقدمها الطلاب والمعلمون حول تطوير المقررات الدراسية بما يجعلها جاذبة لهم. × تدعيم المنهج بالمعلومات التي تتناسب مع خصائص المرحلة العمرية للطالب.

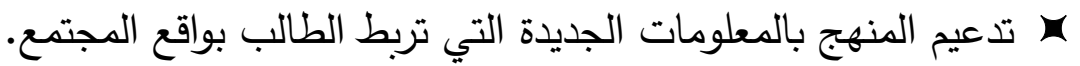


× تثـكيل لجـان مـن الخبـراء التربـويين لتحقيـق التكامـل بـين المـواد الدراسـية تجنبـا

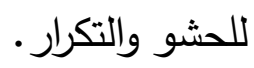

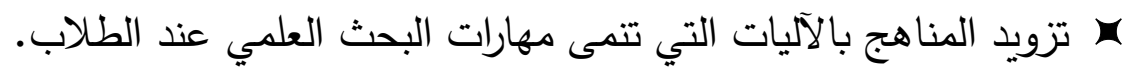
ع-آليات توفير المتطلبات التربوية الفاصة بطرو التندريسر: يمكن توفير المتطلبات الخاصة بطرق التدريس بالاعتماد على الإجراءات التالية:

$$
\text { تزويد غرفة الصف بالتقنيات الحديثة. }
$$

جـ تدريب المعلمين على الوسائل التعليمة الحديثة التي تساعد على فهم المنهج ومحتواه.

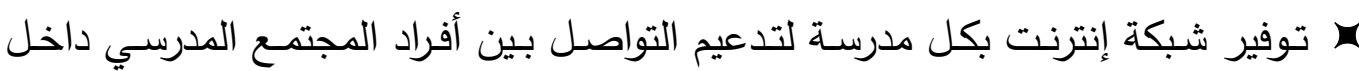
الدرسة وبينهم وبين المنظومة التعليمية ككل خارج المدرسة. ) توفير مراكز مصادر مختلفة للتعلم كالدكتبات ونوادي التكنولوجيا وشبكة المعلومات.

\section{0- آليات توفير المتطلبات التربوية الخاصة بالمبنه:}

يمكن توفير المتطلبات الخاصة بالمبنى بالاعتماد على الإجراءات التالية:

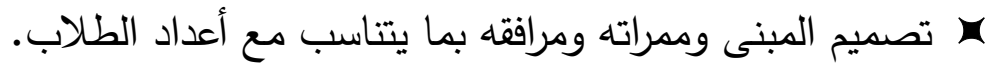
(ج) تجيز مختبرات ومعامل مجهزة بالأدوات الحديثة.

× تجهيز ملاعب وحدائق مناسبة لممارسة الأنشطة والألعاب المختلفة التي تجذب الطلاب. تزويد الفصول بمقاعد وطاولات مريحة للطلاب.

\section{1-1آليات توفير المتطلبات التربوبية الفاصة بالطالب:}

يمكن توفير المتطلبات الخاصة بالطالب بالاعتماد على الإجراءات التالية: ج ( تنفيذ برامج تدريبية لتمكين الطلاب من التعامل مع التقنية الحديثة. × عقد ورش عمل لتدريب الطلاب على كيفية المشاركة في صناعة واتخاذ القرارات الدرسية.

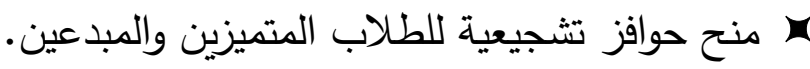
(إفساح المجال أمام الطلاب لممارسة التعلم الذاتي والتعبير عن آرائهم بحرية. -V يمكن توفير المتطلبات الخاصة بالأنثطة بالاعتماد على الإجراءات التالية:

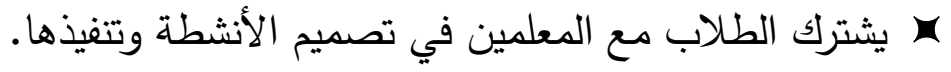

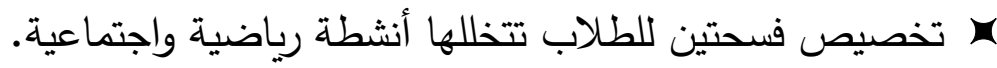




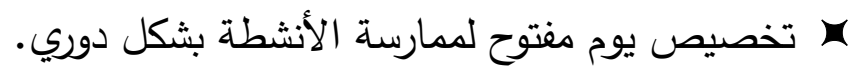

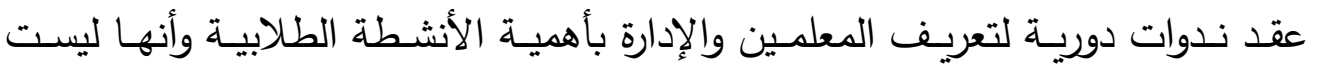

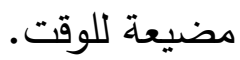
تخصيص رائد نشاط متفرغ لممارسة الأنشطة المدرسية.

\section{^-1آليات توفير المتطابات التربوية الفاصة بالمشاركة المجتمعية:}

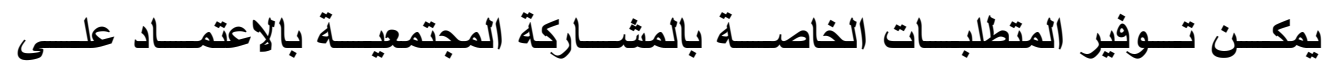

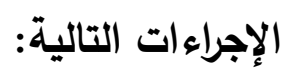

× عقد لقاءات دورية لمجالس الآباء في مواعيد مناسبة للمساهمة في حل المشكلات الددرسية.

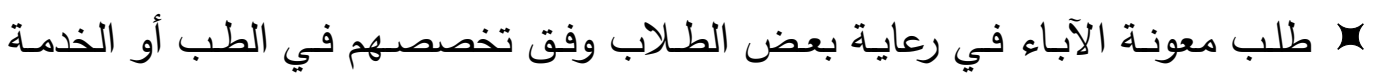
الاجتماعية أو غيره.

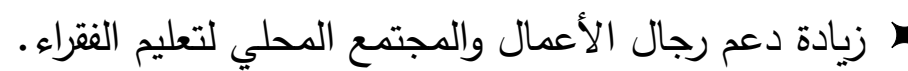
عقد ندوات لزيادة وعي الناس بأهمية المشاركة المجتمعية في المؤسسات التعليمية. بتفيذ رحلات ميدانية على أرض الواقع لربط الطالب والمدرسة بالبيئة المحيطة.

\section{ثالثاً : متطلبات نجاح البيئة المدرسية الجاذبة:}

يتطلب تنفيذ التصـور المقترح اتخـاذ مجموعـة مـن الإجراءات لضـمان نجـاح البيئة

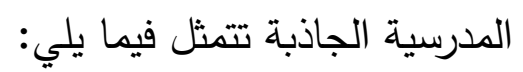

تخصيص الاعتمـاد والموازنـات الماليـة اللازمـة لنظـام البيئة المدرسية الجاذبـة سواء

$$
\text { كانت حكومية أو غير حكومية. }
$$

مراعاة المهام والمسئوليات الوظيفية لمعلمي وطلاب مدارس الحلقة الثانية من التعليم الأساسي عند التخطيط لنظام البيئة المدرسية الجاذبة. التركيز على التوعية الإعلامية بأهمية نظام البيئة الددرسية الجاذبة.

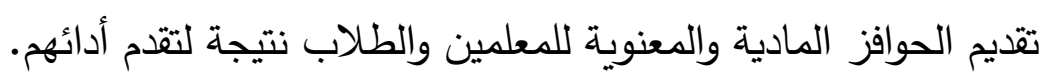
الحد من المركزية ومنح مديري الددارس مزيداً من الصلاحيات وإثراكهم في صنع القرارات.

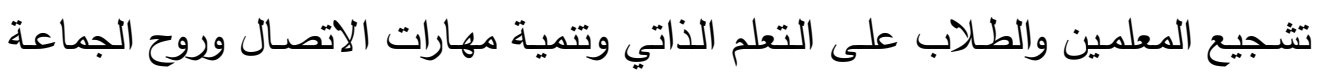
في العمل. التقويم المستمر لكل مكونات نظام البيئة الددرسية الجاذبة لضمان استمرارية فعاليته. 


\section{المسراج}

1- ابن منظور ، محمد ابن مكرم (ץ +. ץ): لسـان العرب، إعداد وتصنيف: يوسف خياط،

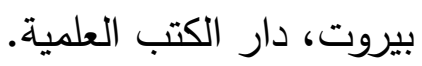

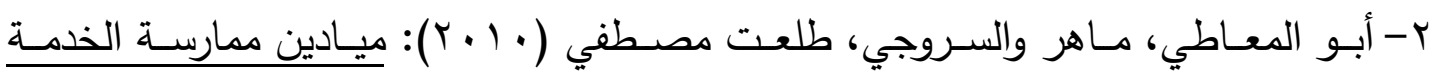

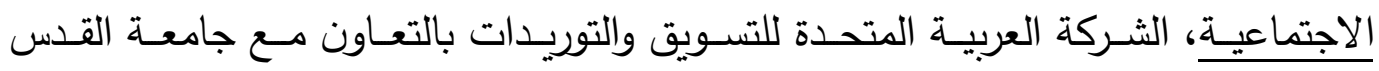

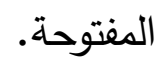

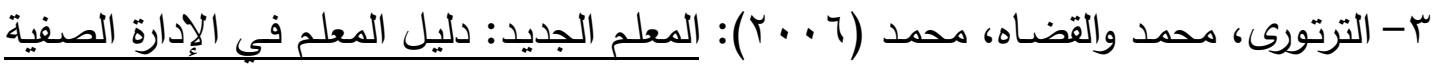

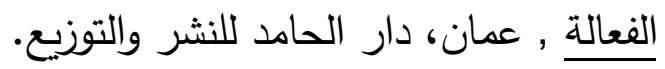

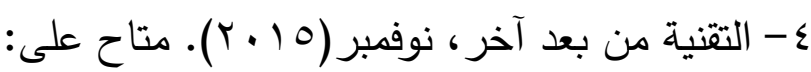

http://k4technology.blogspot.com.eg/2015 11 01 archive.html

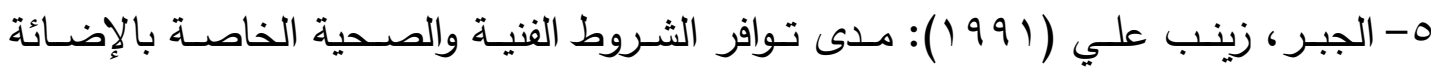

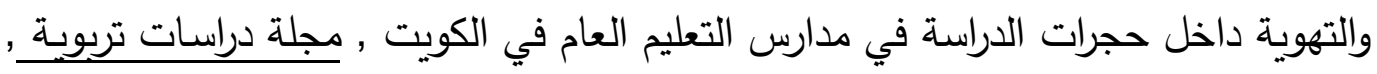

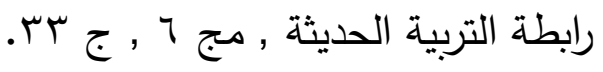

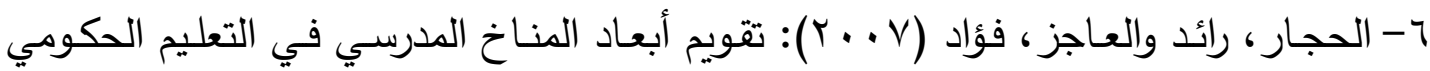

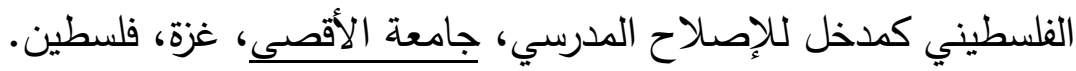

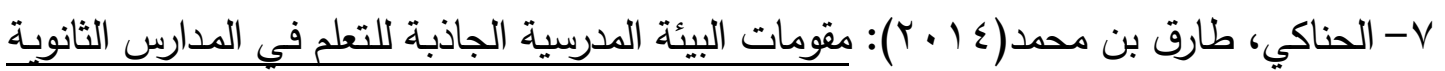

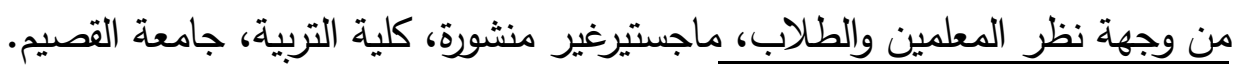

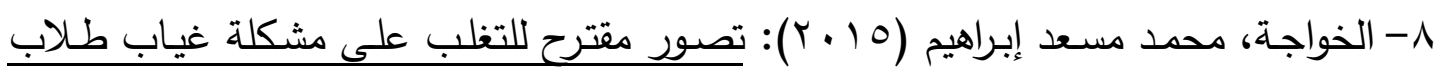

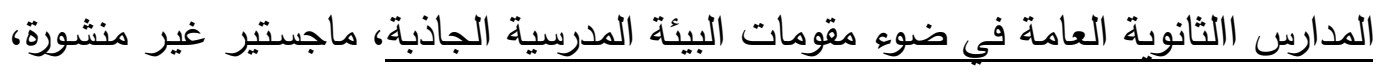

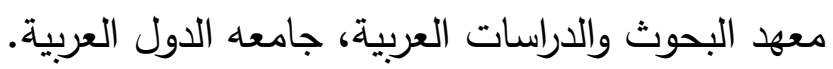

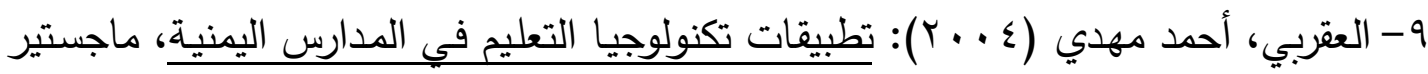
غير منشورة، كلية التربية، جامعة عدن. (بان.

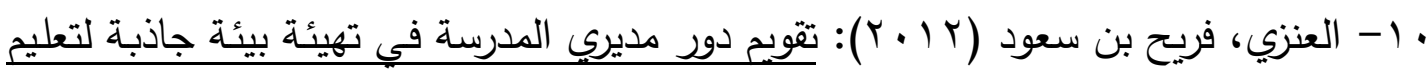

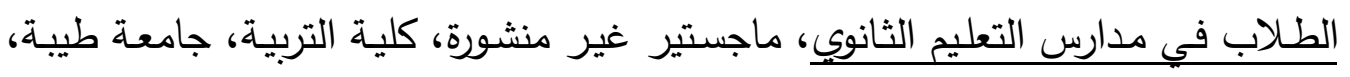
المدينة المنورة. - المفي

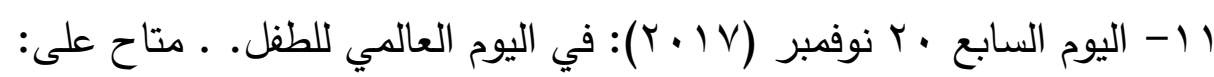
http://www.youm7.com/story/2017/11/20

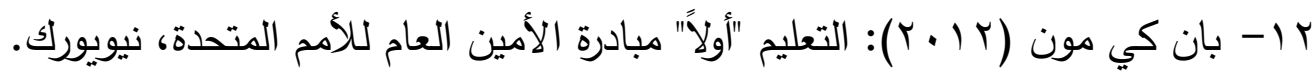

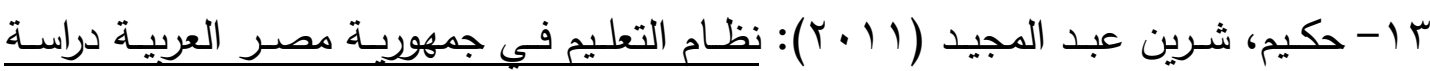
مقارنة، دكتوراه غير منشورة، جامعة أم القرى، كلية التربية قسم الإدارة التربوية والتخطيط. 


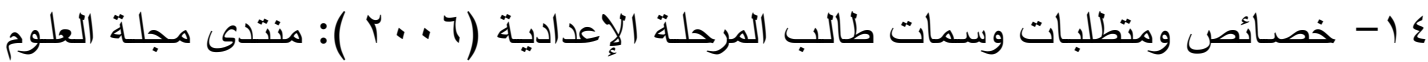

http://swmsa.net/forum/showthread.php?t=5954

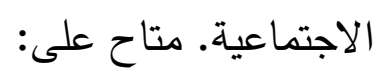

$$
10 \text { - خصائص نمو التلاميذ في المرحلة الإعدادية. متاح على: }
$$

https://sites.google.com/site/eqsaea/l1

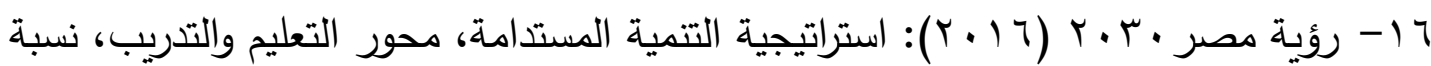

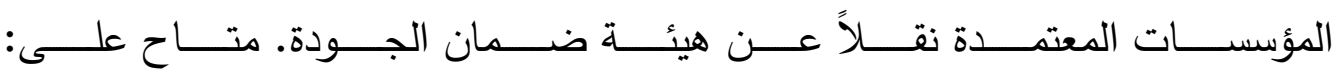

http://sdsegypt2030.com

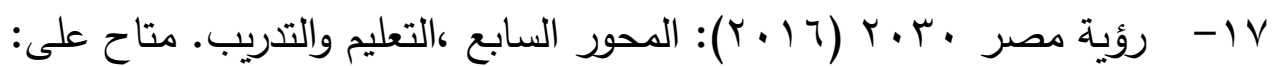

http://sdsegypt2030.com/wp-content/uploads/2016/05

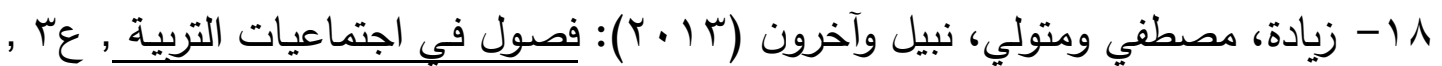
ط. 1, مكتبة الرشد للنشر والتوزيع , الرياض.

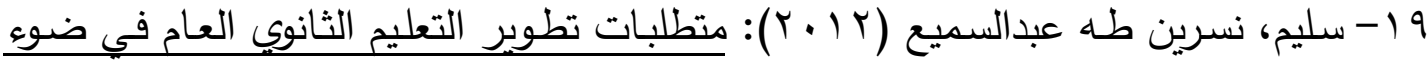

تحديات القرن العشرين , ماجستير غير منشورة , كلية التربية, دمياط.

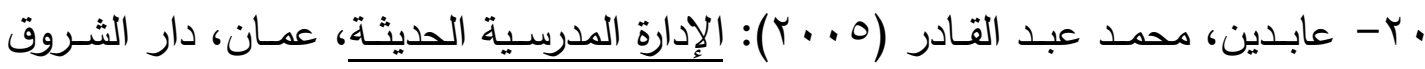

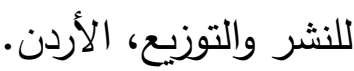

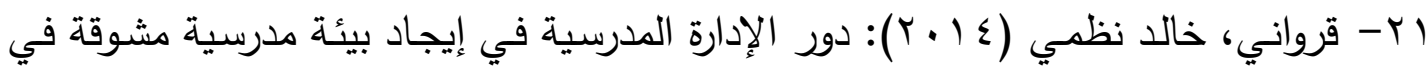

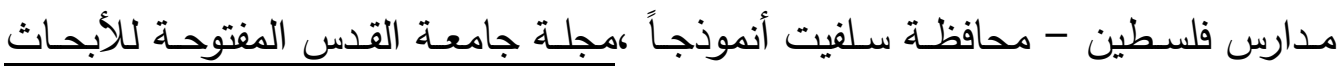

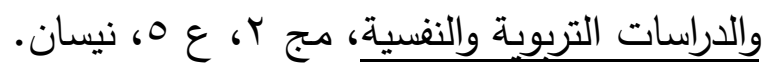

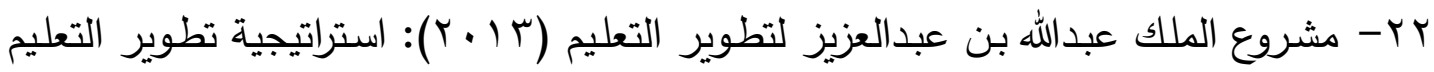

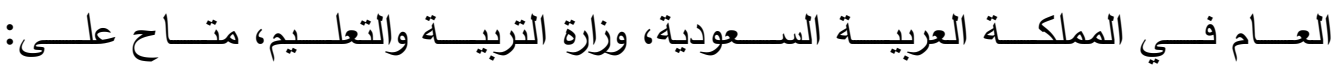
http://www.tatweer.edu.sa/sites/default/files/tatweerpublication/for ms20\% for20\%developing20\%schools.pdf.15/7/2025

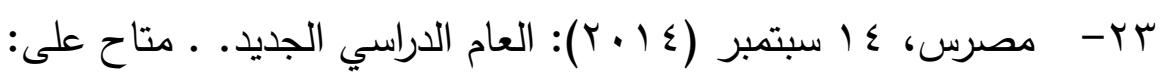
https://www.masress.com/october/202151

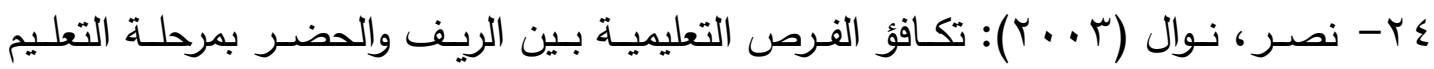

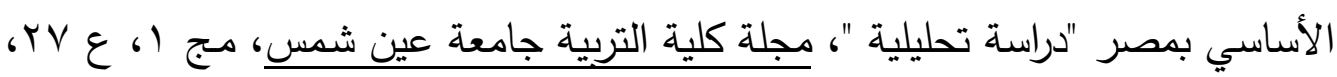

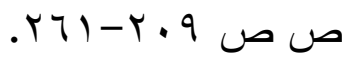

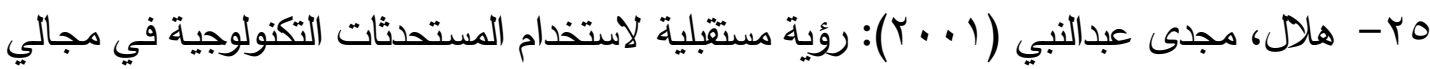

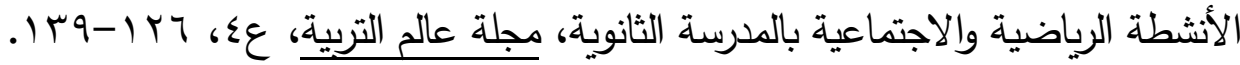


26- Blank, R., Levine, R. \& Steel, L. (1996): After Fifteen Years: Magnet Schools in urban Education, Culture, institutions, \& The Unequal Effects of School Choice, New York, Teachers College Press.

27- Byamugisha, A. (2011): Examining the effects of School Environmental factors on Pupils Learning Achievement in Ugandan Primary Schools, paper presented at the Annual Meeting of the Annual Conference of the Comparative and International Education Society, Fairmont Le Reine Elizabeth, Montreal, Quebec, Canada, Apr 30.

28- Clinchy ,E.( 1995): The changing nature of our magnet schools. New Schools, Vol. (11), No. (2).

29- Colbert, Cortney Alan (2007): Understanding the Current Educational Climate in California Arts Magnet Schools, M.A., University of Arizona, USA.

30- DePree, M.(1989): Leadership is an Art: New York, Bantam Doubleday Dell.

31- Florida, Richard (2007): The Rise of the Creative Class and How it is Transforming Work Leisure, Community and Everyday Life, New York, Basic.

32- Goldring, E. \& Smrekar, C. (2002): Magnet Schools: Reform and Race in Urban education, The Clearing House, Vol. 76, No. 1.

33- Guthrie, James (2003): Encyclopedia of Education, $2^{\text {nd }} \mathrm{ed}$, Macmillan Inc. USA.

34- Han, Alyson Kim (2007): Status of teaching elementary science For English learners in Science, Mathematics and technology centered magnet School, Ed. D, University of southern California University,USA.

35- Harris, R. M. (1993): Perceptions about Adult Caregivers in an Urban Elementary Community Magnet School of the Arts, Pd.D., Columbia University Teachers College.

36- Higgins, S. (2005): The Impact of School Environments: A literature review, The Centre for Learning and Teaching School of Education, Communication and Language Science, University of Newcastle.

37- Hoy, W. \& Miskel, C. (2005): Education Administration: Theory, Research \& Practice, New York, McGraw Hill.

38- Kelly, Bennett (2008): Can Magnet School Performance and Student Body Family Income be Predicted for Neighborhood Revitalization Purposes? Greensboro, USA. 
39- Magnet schools of America. Available at: http://www.magnet.edu

Accessed on: jan: 2016

40- Magnet schools of America mission \& beliefs. Available at:

http://www.magnet.edu/about/our-mission-and-beliefs

Accessed on: jan: 2016

41- McKenna, James Corey (2007) : The Development and Implementation of an Integrated Curriculum at an Elementary Math, Science, and Technology Magnet School, $\mathrm{PhD}$,University of California, Santa Barbara, USA.

42- Mitchell, Anne Mitchell (2004): Monitoring desegregation: Intercultural relations in six Midwestern magnet schools, unpublished M.A., University of Minnesota, USA.

43-National Center for Education Statistics, 288 NCES Statistical Analysis Report. Available at: www.nces.ed.gov/pubs. Accessed On: May 6, 2016.

44-National Education Association (2007): It's Time for A Change: Voices from America's Classroom, Washington DC.

45- Public School review: What is a Magnet School?. Available at: https://www.publicschoolreview.com/blog/what-is-a-magnet-school Accessed on: jan: 2017.

46- Reed, Vonda Lakecia (2004): A comparative Analysis of the Academic Performance of Black Students in Elementary Magnet Versus Elementary non- magnet school in North Carolina, Ed.D, Fayetteville State University, USA.

47- Straus, Ryane Mcauliffe (2005): Reconstructing Magnet School: Social Construction and the Demise of Desegregation, $\mathrm{PhD}$, University of California, Irvine, USA.

48-United States Department of Education (2004): Innovations in Education: Creating Successful Magnet School Programs. September.

49- Villarreal, Minerva Medrano (2006): From separate but equal to tracking to choice: Perceptions of Ddifferent Sstakeholders on the Iimpact Magnet School on High School Students, Ed. D, The University of Texas pan American, USA. 


\section{Abstract}

The current study aimed to identify the educational requirements to achieve an attractive school environment in schools of the second cycle of basic education in Menoufia in view of the requirements of the magnet school in terms of eight dimensions: student, teacher, curriculum, teaching methods, activities, buildings, school administration and community participation. The study sought to answer some questions, including the degree of availability of educational requirements to achieve an attractive school environment in schools of the second cycle of basic education in Menoufia governorate, and the effect of variables (specialization - place of school) on the level of availability of these requirements. The study sample consisted of 525 teachers. The results showed that the educational requirements for achieving an attractive school environment in schools of the second cycle of basic education in the governorate were weak, and that there are statistical differences between the availability of these requirements from the point of view of the teachers of scientific materials and their counterparts of literary materials teachers for the teachers of scientific materials. Whereas there are no statistical differences between the availability of those requirements from the point of view of teachers in schools of the second cycle of basic education in the countryside and their counterparts in urban schools. In light of the results of the study and in light of the requirements of the attractive school the study presented a proposed scenario to achieve an attractive school environment in schools of the second cycle of basic education in Menoufia governorate in the future. 